\title{
La familia Nyctaginaceae (Caryophyllales) en Aguascalientes, México
}

\section{The Nyctaginaceae family (Caryophyllales) in Aguascalientes, Mexico}

\section{Acta Botanica Mexicana}

\author{
Manuel Higinio Sandoval-Ortegal,3(iD, María Elena Siqueiros-Delgado' (ID, Rosa Cerros-Tlatilpa(iD y Gilberto Ocampo'(iD)
}

\section{Resumen:}

Antecedentes y Objetivos: La familia Nyctaginaceae se distribuye en regiones cálidas del mundo, principalmente en el suroeste de Norteamérica y está integrada por aproximadamente 31 géneros y 405 especies. Para México se reportan 18 géneros y alrededor de 110 especies. El objetivo del presente estudio fue realizar el tratamiento taxonómico y documentar las especies de Nyctaginaceae presentes en el estado de Aguascalientes.

Métodos: Se realizaron colectas de agosto 2012 a junio 2015 en distintos sitios del estado de Aguascalientes, en los que fueron registradas las coordenadas geográficas y el tipo de vegetación. El material colectado fue identificado por medio de claves taxonómicas y cotejado con material de herbario. Para el tratamiento taxonómico se elaboraron descripciones para familia, géneros y especies, claves dicotómicas para su identificación y mapas de distribución con base en los datos tomados en campo y de los ejemplares de herbario consultados.

Resultados clave: En Aguascalientes la familia Nyctaginaceae está representada por seis géneros y 15 especies, dos de ellas nuevos registros para la flora del estado: Commicarpus scandens y Pisonella arborescens. El género con mayor número de especies es Mirabilis con seis, seguido por Boerhavia con cuatro y Allionia con dos.

Conclusiones: Dentro del estado, la mayor cantidad de especies de Nyctaginaceae se encuentra en los municipios Asientos y Tepezalá, en matorral xerófilo. El presente estudio contribuye al conocimiento de la flora de Aguascalientes y de la familia Nyctaginaceae en México.

Palabras clave: inventario florístico, nuevos registros, taxonomía.

\section{Abstract:}

Background and Aims: The Nyctaginaceae family is distributed in warm regions of the world, mainly in the southwest of North America and is composed by approximately 31 genera and 405 species. For Mexico, 18 genera and about 110 species are reported. The aim of the present study was to perform the taxonomic treatment and to document the Nyctaginaceae species present in the state of Aguascalientes.

Methods: Collections were carried out from August 2012 to June 2015 at different sites in the state of Aguascalientes, in which the geographic coordinates and the type of vegetation were registered. The collected material was identified by means of taxonomic keys and collated with herbarium material. For taxonomic treatment, descriptions for family, genera and species, dichotomous keys for their identification and distribution maps were elaborated based on data taken in the field and from the herbarium specimens consulted.

Key results: In Aguascalientes the family Nyctaginaceae is represented by six genera and 15 species, two of which are new records for the state's flora: Commicarpus scandens and Pisoniella arborescens. The genus with the highest number of species is Mirabilis with six, followed by Boerhavia with four and Allionia with two.

Conclusions: Within the state, the largest number of Nyctaginaceae species is found in the Asientos and Tepezalá municipalities, in xerophilous scrub. The present study contributes to the knowledge of the flora of Aguascalientes and the family Nyctaginaceae in Mexico.

Key words: floristic inventory, new records, taxonomy.

\footnotetext{
${ }^{1}$ Universidad Autónoma de Aguascalientes, Departamento de Biología, Centro de Ciencias Básicas, Herbario HUAA, Avenida Universidad 940, Ciudad Universitaria, 20131 Aguascalientes, Aguascalientes, México. ${ }^{2}$ Universidad Autónoma del Estado de Morelos, Facultad de Ciencias Biológicas, Laboratorio de Sistemática y Morfología, Av. Universidad 1001, Col. Chamilpa, 62210 Cuernavaca, Morelos, México.

${ }^{3}$ Autor para la correspondencia: m.higinio.s@hotmail. com
}

Recibido: 5 de febrero de 2020.

Revisado: 24 de febrero de 2020.

Aceptado por Rosario Redonda Martínez: 27 de mayo de 2020.

Publicado Primero en línea: 12 de junio de 2020.

Publicado: Acta Botanica Mexicana 127 (2020).

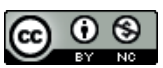

Este es un artículo de acceso abierto bajo la licencia Creative Commons 4.0 Atribución-No BY-NC 4.0 International).
Citar como: Sandoval-Ortega, M. H., M. E. SiqueirosDelgado, R. Cerros-Tlatilpa y G. Ocampo. 2020. La familia Nyctaginaceae (Caryophyllales) en Aguascalientes, México. Acta Botanica Mexicana 127: e1673. DOI: 10.21829/abm127.2020.1673 


\section{Introducción}

La familia Nyctaginaceae se distribuye en los trópicos y otras regiones cálidas del mundo, principalmente en el neotrópico y zonas áridas de Norteamérica (Stevens, 2001; Douglas y Spellenberg, 2010; Judd et al., 2016). Actualmente se reconocen 7 tribus para esta familia: Leucastereae, Boldoeae, Colignonieae, Bougainvilleeae, Pisonieae, Nyctagineae y Caribeeae (Douglas y Spellenberg, 2010), con un total aproximado de 31 géneros y 300-405 especies (Stevens, 2001; Hernández-Ledesma et al., 2015; Judd et al., 2016). Entre los géneros con mayor número de especies se encuentra Neea Ruiz \& Pav. (80-85), Guapira Aubl. (60-70) y Mirabilis L. (55-50) (Stevens, 2001; Judd et al., 2016). Varias especies de los géneros Abronia Juss., Bougainvillea Comm. ex Juss. y Mirabilis son cultivadas como ornamentales (Judd et al., 2016).

En México, la familia Nyctaginaceae ha sido estudiada principalmente en la zona centro-sur, específicamente en el estado de Guerrero (Zavala-Téllez y Fonseca, 2014), Hidalgo (Hernández-Ledesma y Flores-Olvera, 2003) y Veracruz (Fay, 1980), la región del Bajío (Spellenberg, 2001), el valle de México (Calderón de Rzedowski, 2005), la cuenca del río Balsas (Pérez-Alvarado et al., 2000) y el valle de TehuacánCuicatlán (Hernández-Ledesma, 2018). Hasta el momento, se reportan 18 géneros y alrededor de 110 especies en el país (Villaseñor y Espinosa-Garcia, 2004; Villaseñor, 2016). A pesar del esfuerzo por conocer la diversidad y distribución de Nyctaginaceae en México, no se sabe con claridad su diversidad en la región centro-norte, por lo que es necesario realizar estudios que permitan dar a conocer la riqueza de especies de la familia en esta zona importante del territorio nacional, que es en donde se encuentra Aguascalientes.

Desde el punto de vista florístico, Aguascalientes tiene representantes de 27 órdenes de eudicotiledóneas, Caryophyllales es uno de los que mayor cantidad de familias presenta en la región (García-Regalado et al., 1999; CONABIO, 2008). Aunque se han realizado varios estudios sobre la flora del estado (de la Cerda-Lemus, 1989, 1996, 2004a, b, 2011a, b; Siqueiros-Delgado, 1989, 1996; Siqueiros-Delgado y González-Adame, 2006; Siqueiros-Delgado et al., 2011; Martínez-Calderón et al., 2017; Sandoval-Ortega et al., 2017, 2019; Sandoval-Ortega y Siqueiros-Delgado, $2018,2019)$, algunas familias aún necesitan ser revisadas para determinar el número de especies y la situación de sus poblaciones. A partir de agosto de 2012 y hasta abril de 2017 se llevó a cabo el proyecto "Inventario florístico de familias selectas de dicotiledóneas del estado de Aguascalientes" (JF140 CONABIO) y, actualmente, se está trabajando en la flora de eudicotiledóneas del estado, de donde se desprende el presente trabajo.

El objetivo de este estudio fue realizar un tratamiento taxonómico para la identificación y documentación de los géneros y especies de Nyctaginaceae presentes en Aguascalientes y contribuir al conocimiento de la familia Nyctaginaceae en México, dando a conocer la riqueza y distribución de esta familia en el estado.

\section{Materiales y Métodos}

\section{Área de estudio}

Aguascalientes se encuentra ubicado en la zona centronorte de la República Mexicana, posee una extensión de $5680 \mathrm{~km}^{2}$, que representan aproximadamente $0.3 \%$ de la superficie nacional (CONABIO, 2008) y cuenta con 11 municipios (Fig. 1). El estado se encuentra en la región neártica y convergen en su territorio tres provincias biogeográficas: Desierto Chihuahuense (que cubre la mayor superficie del estado), Sierra Madre Occidental (que se encuentra al oeste principalmente en San José de Gracia y parte de Calvillo) y Tierras Bajas del Pacífico (que cubre una pequeña área al suroeste del estado, al oeste de Calvillo) (Morrone et al., 2017).

En general, el clima de Aguascalientes es semiseco (BS) (García, 1964) con varios subtipos. Semiseco templado $(\operatorname{BS} 1 \mathrm{hw}(\mathrm{w}))$, abarca $80 \%$ del territorio; mientras que semiseco semicálido (BS1hw) se extiende en parte de los municipios del sur, sureste y centro de la entidad. Hacia el noreste, en el municipio Asientos, se encuentra una pequeña franja con un clima seco semicálido (BSOhw(w)) y en Calvillo se localizan zonas con clima semicálido subhúmedo ((A) CW) (SPP, 1981).

Los grupos climáticos presentan sus respectivas comunidades vegetales predominantes: 1) zona árida cubierta por vegetación xerofítica, ubicada en la porción central del estado y formada en su mayoría por matorrales secundarios y pastizales que reemplazaron a los mezquitales, pastizales o nopaleras originales; 2) templada ubicada en la región 


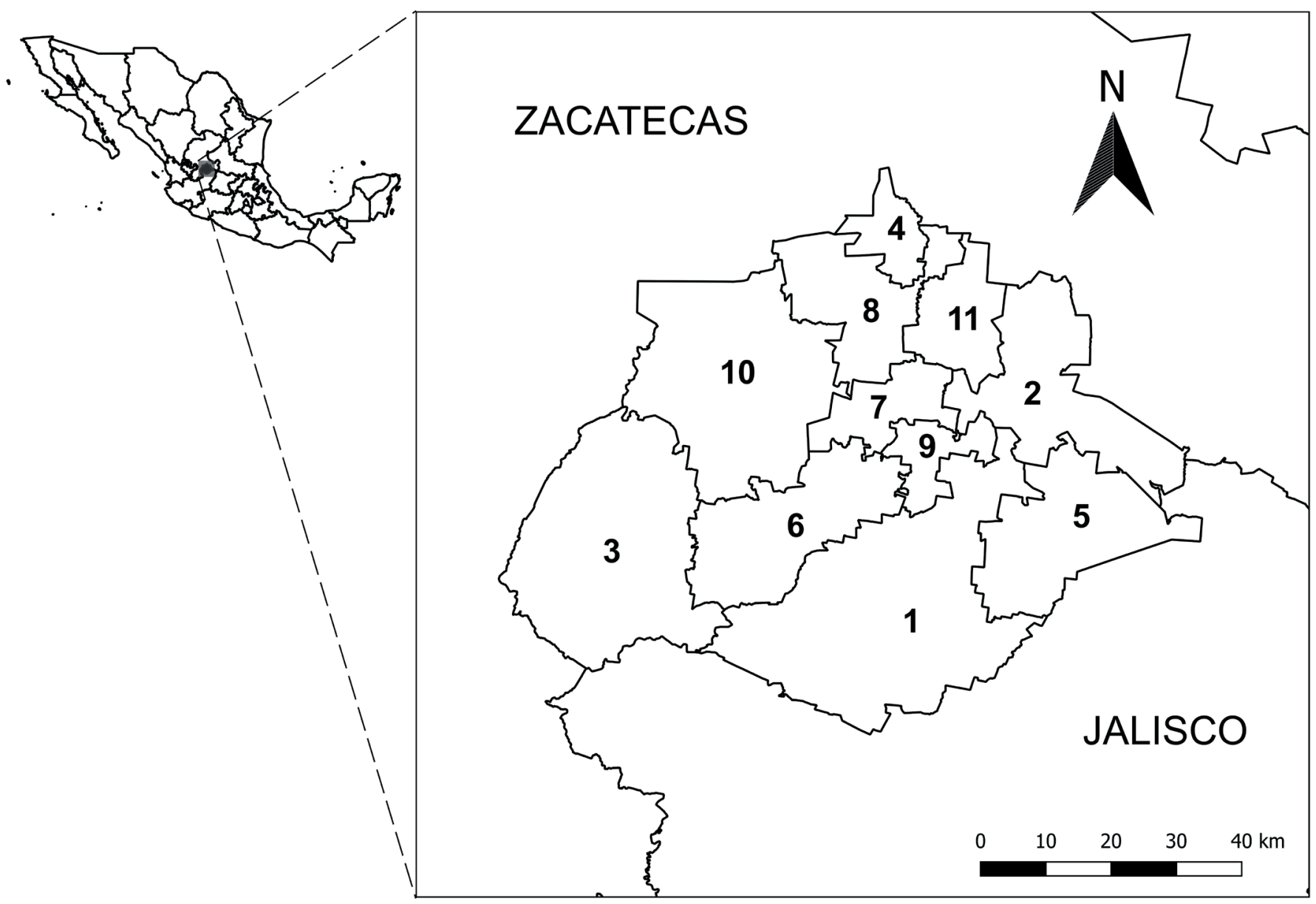

Figura 1: Municipios del estado de Aguascalientes, México. 1. Aguascalientes; 2. Asientos; 3. Calvillo; 4. Cosío; 5. El Llano; 6. Jesús María; 7. Pabellón de Arteaga; 8. Rincón de Romos; 9. San Francisco de los Romo; 10. San José de Gracia; 11. Tepezalá.

montañosa al oeste del estado, que alberga diferentes tipos de bosques de encino o bosques mixtos (encino-coníferas) y 3) tropical, al suroeste de la entidad, cubierta en su mayoría por matorrales subtropicales secundarios que han sustituido a las comunidades prístinas de selva baja caducifolia, la cual queda como relicto en algunas áreas conservadas ( $\mathrm{Si}$ queiros-Delgado et al., 2016).

\section{Colecta e identificación de material}

En el periodo comprendido entre agosto de 2012 y diciembre de 2015 se efectuaron exploraciones de colecta de plantas en todo el estado de Aguascalientes siguiendo la metodología propuesta por Engelmann (1986). En cada sitio de colec- ta se tomaron coordenadas geográficas con base en Datum WGS 84 (DMA, 1991) y se registró el tipo de vegetación de acuerdo con la propuesta de Siqueiros-Delgado et al. (2017). Se colectaron 110 ejemplares, que fueron depositados en el Herbario de la Universidad Autónoma de Aguascalientes (HUAA), con hasta cuatro duplicados que fueron enviados al Herbario del Centro Interdisciplinario de Investigación para el Desarrollo Integral Regional, Unidad Durango (CIIDIR), Herbario Luz María Villarreal de Puga (IBUG), Herbario del Instituto Nacional de Estadística y Geografía (INEGI) y el Herbario Nacional de México (MEXU); los acrónimos de los herbarios mencionados corresponden a los registrados en Index Herbariorum (Thiers, 2019). 
El material colectado fue identificado por medio de claves taxonómicas especializadas (Standley, 1911, 1918; Standley y Steyermark, 1946; Fay, 1980; Harriman, 1999; Pérez-Alvarado et al., 2000; Spellenberg, 2001, 2003; Hernández-Ledesma y Flores-Olvera, 2003; Calderón de Rzedowski, 2005; Zavala-Téllez y Fonseca, 2014; HernándezLedesma, 2018) y cotejado en el Herbario HUAA. Además, se revisaron los ejemplares depositados en el Herbario del Instituto de Ecología, A.C. (IEB) y en el Herbario Nacional de México (MEXU). Se consultaron también las colecciones en línea de los herbarios Botanischer Garten und Botanisches Museum Berlin (Curators Herbarium B, 2020), Kew Royal Botanic Gardens (K, 2018), Missouri Botanical Garden (MO) (TROPICOS, 2018), Muséum national d'Histoire naturelle (P, 2018), New York Botanical Garden (NY, 2018), Smithsonian Institution (US, 2018), así como la plataforma Global Plants (JSTOR, 2018).

\section{Tratamiento taxonómico}

Para el tratamiento taxonómico se elaboraron descripciones morfológicas de la familia, géneros y especies con base en la secuencia utilizada por Spellenberg (2003), así como claves dicotómicas para su identificación. En cuanto a los nombres aceptados y su sinonimia, se tomaron en cuenta las propuestas de Spellenberg $(2001,2003)$ y HernándezLedesma (2018). Se elaboraron mapas de distribución para las especies por medio del programa QGIS v. 2.28.4 (QGIS, 2017), utilizando los datos tomados en campo y de los ejemplares de herbario consultados; aquellos que no contaban con esa información se les asignaron coordenadas de acuerdo con la localidad de colecta con el programa Google Earth Pro (Google Earth, 2019). Para cada especie se elaboró una lámina con fotografías que muestran el hábito y características morfológicas importantes para su identificación.

\section{Resultados}

Para el estado de Aguascalientes se reconocen dos tribus, seis géneros y 15 especies de la familia Nyctaginaceae. El género con mayor número es Mirabilis con seis, seguido por Boerhavia L. con cuatro y Allionia L. con dos, mientras que los demás géneros están representados por solo una. Todas las especies son nativas y dos son registros nuevos para la flora del estado de acuerdo a listados conocidos para esta familia (García-Regalado et al., 1999; Villaseñor, 2016). Los municipios en los que se distribuye la mayor cantidad de taxones son Asientos y Tepezalá, con 10 cada uno, seguidos por Calvillo con nueve y Aguascalientes con ocho; mientras que el tipo de vegetación que presenta mayor cantidad es matorral xerófilo con un total de 13 (Cuadro 1).

\section{Taxonomía}

\section{Nyctaginaceae}

Plantas anuales o perennes, herbáceas, sufruticosas, arbustivas, rara vez arborescentes; tallos postrados a ascendentes, cilíndricos, en ocasiones con crecimiento secundario originado por variantes cambiales, glabros a pubescentes, inermes o espinosos; hojas opuestas, subopuestas o alternas, pecioladas a sésiles, simples; láminas foliares, membranosas o coriáceas, comúnmente enteras; inflorescencias cimas, panículas, umbelas, racimos, glomérulos o flores solitarias, terminales o axilares, pedunculadas a subsésiles, rara vez sésiles; brácteas presentes o ausentes, cuando presentes separadas o fusionadas formando un involucro subyacente a una flor o glomérulo; flores actinomorfas o zigomorfas, bisexuales o unisexuales, generalmente pentámeras, sésiles, perianto de tépalos fusionados en un tubo corto o alargado, porción basal generalmente modificada, de distinto color, encerrando el ovario y la base de los estambres, porción distal con apariencia de corola, por lo común 5 lobulada; estambres (2)3-5(10), filamentos iguales o subiguales en longitud, fusionados basalmente en un anillo corto alrededor del ovario; ovario súpero, carpelo 1, estilo filiforme, largo, por lo común excerto, estigma capitado o fimbriado; placentación basal, óvulo 1 estipitado o sésil; fruto un aquenio encerrado por la base modificada y endurecida del perianto formano un antocarpo coriáceo, rara vez carnoso, ovoide, claviforme o comprimido dorsoventralmente, liso o con 5-10 costillas; semilla 1 por fruto, endospermo escaso y perispermo usualmente abundante, almidonado, testa delgada adherida al fruto; embrión curvado alrededor del endospermo, rara vez recto. 
Cuadro 1: Tribus, géneros y especies de la familia Nyctaginaceae presentes en Aguascalientes, México. Municipios: AGS=Aguascalientes, ASIE=Asientos, $\mathrm{CAL}=$ Calvillo, COS=Cosío, JM=Jesús María, ELL=El Llano, PA=Pabellón de Arteaga, RR=Rincón de Romos, SFR=San Francisco de los Romo, SJG=San José de Gracia, TEP=Tepezalá. Vegetación: BQ=bosque de Quercus, BG=bosque de galería, BT=bosque tropical caducifolio, MST=matorral subtropical, $\mathrm{MX}=$ matorral xerófilo, $\mathrm{P}=$ pastizal, VS=vegetación secundaria (arvense, ruderal o de zonas urbanas). * =Registro nuevo para el estado.

\begin{tabular}{|c|c|c|c|}
\hline Tribu & Especie & Municipio & Vegetación \\
\hline \multirow[t]{14}{*}{ Nyctagineae } & Allionia choysi Standl. & AGS, ASIE, CAL, ELL, SFR, TEP & MX, VS \\
\hline & A. incarnata $\mathrm{L}$. & ASIE, TEP & $\mathrm{MX}$ \\
\hline & Boerhavia anisophylla Torr. & ASIE, TEP, ELL & $\mathrm{MX}$ \\
\hline & B. coccinea Mill. & $\begin{array}{l}\text { AGS, ASIE, CAL, COS, JM, RR, SJG, } \\
\text { TEP }\end{array}$ & $\mathrm{MX}, \mathrm{BT}, \mathrm{MST}, \mathrm{VS}$ \\
\hline & B. erecta $\mathrm{L}$. & CAL & MST, BT \\
\hline & B. gracillima Heimerl. & AGS, ASIE, COS, TEP & $\mathrm{MX}, \mathrm{P}$ \\
\hline & *Commicarpus scandens (L.) Standl. & AGS, CAL & MST, MX, BG \\
\hline & Cyphomeris gypsophiloides (M. Martens \& Galeotti) Standl. & ASIE & $\mathrm{MX}$ \\
\hline & Mirabilis aggregata (Ortega) Cav. & AGS, ASIE, TEP & $\mathrm{MX}$ \\
\hline & M. glabrifolia (Ortega) I.M. Johnst. & AGS, ASIE, CAL, JM, SFR, SJG, TEP & $\mathrm{MX}, \mathrm{MST}, \mathrm{P}$ \\
\hline & M. jalapa L. & AGS, ASIE, CAL, ELL, PA, TEP & MX, VS \\
\hline & M. linearis (Pursh) Heimerl & COS, ELL, RR, SFR, SJG & $B Q, M X$ \\
\hline & M. longiflora L. & CAL, SJG, TEP & $\mathrm{BQ}, \mathrm{MST}, \mathrm{MX}$ \\
\hline & M. viscosa Cav. & AGS, ASIE, CAL, JM, SFR, SJG, TEP & $B Q, B G, M S T, M X, P, V S$ \\
\hline Pisonieae & *Pisoniella arborescens (Lag. \& Rodr.) Standl. & CAL & BT \\
\hline
\end{tabular}

Clave para los géneros de Nyctaginaceae presentes en Aguascalientes

1a. Flores rodeadas por brácteas fusionadas al menos basalmente, formando un involucro; base del perianto oculta por el involucro durante la antesis..... 2

1b. Flores rodeadas por brácteas libres o ausentes, sin formar un involucro; base del perianto descubierta durante la antesis 3

2a. Brácteas del involucro 3; flores zigomorfas, 3 por involucro, antesis simultánea aparentando una sola flor Allionia L.

2b. Brácteas del involucro 5; flores actinomorfas, 1-3(6) por involucro, cuando hay más de 1 entonces de antesis no simultánea sin aparentar una sola flor

Mirabilis L.

3a. Plantas arbustivas; inflorescencias en forma de umbela

3b. Plantas herbáceas o subfruticosas; inflorescencias en forma de racimos, cimas o panículas 5

4a. Pedicelos pubescentes, 0.5-2(3) mm largo; base del tubo del perianto no constreñido por encima del ovario Pisoniella (Heimerl) Standl.

4b. Pedicelos glabros, $\geq 7 \mathrm{~mm}$ de largo; base del tubo del perianto evidentemente constreñida por encima del ovario Commicarpus Standl.

5a. Inflorescencias racimos laxos; antocarpo glabro, de simetría bilateral Cyphomeris Standl.

5b. Inflorescencias cimas laxas o densas simulando una umbela compacta o glomérulo; antocarpo liso o glanduloso, de simetría radial Boerhavia L.

Allionia L., Syst. Nat. ed. 10. 2: 890. 1759. TIPO: Allionia incarnata $L$.

Plantas anuales o perennes, herbáceas; tallos postrados, inermes; hojas opuestas, subiguales, pecioladas subsésiles; láminas foliares membranosas, margen ondulado o crenulado, discoloras, pubescentes; inflorescencias en glomérulos axilares, 3 flores de antesis simultánea que aparentan 1 sola flor, pedunculadas; brácteas 3 , cóncavas, persistentes, fusionadas basalmente formando un invólucro que oculta la base del perianto durante la antesis, acrescentes, extendidas en fruto; flores zigomorfas, bisexuales, sésiles; perianto membranáceo, infundibuliforme, constreñido basalmente por encima del ovario, fuertemente oblicuo, con dos lóbulos dirigidos hacia el centro del conjunto, 
reducidos o ausentes, tres lóbulos dirigidos hacia el exterior, expandidos y emarginados; estambres 4-7, inclusos o exsertos, fusionados en la base; estilo exserto, estigma capitado; antocarpo de simetría bilateral, comprimido dorsoventralmente, con una cara concava y otra convexa, coriáceo, glabro o esparcidamente puberulento, con costillas modificadas.

Género americano con dos especies distribuidas desde Estados Unidos de América hasta Sudamérica y las Antillas (Spellenberg, 2003), ambas presentes en el área de estudio, muy similares en morfología, la diferencia más evidente entre ellas es la forma del antocarpo; en Allionia choisyi Standl. tiene dientes largos y curvos a lo largo de los márgenes, mientras que en $A$. incarnata $\mathrm{L}$. tiene márgenes ondulados o lisos. En Aguascalientes $A$. incarnata es menos común que $A$. choisyi.

Clave para especies de Allionia presentes en Aguascalientes

1a. Antocarpo de margen profundamente dentado A. choisyi Standl.

1b. Antocarpo de margen irregularmente ondulado a liso A. incarnata L.

Allionia choisyi Standl., Publ. Field Mus. Nat. Hist., Bot. Ser. 8(5): 310. 1931. Fig. 2.

इ Allionia incarnata var. glabra Choisy, Prodr. 13(2): 435. 1849. TIPO: MÉXICO. Circa Mexicum in montibus, 1827, J. L. Berlandier 577 (lectotipo: G, isolectotipo: MO-247219!, P-00712488!, P-00712489!, P-00712490!, P-00712491!, designado por Standley, 1911).

इWedeliella glabra (Choisy) Cockerell, Torreya 9: 166. 1909. इ Wedelia glabra (Choisy) Standl., Contr. U.S. Natl. Herb. 12: 332. 1909.

Plantas perennes, herbáceas; tallos postrados a decumbentes, 5-70 cm de largo, vilosos cuando jóvenes, glabrescentes, comúnmente rojizos; pecíolo 2-15(20) mm de largo, con pubescencia y color similar al de los tallos; láminas foliares ovadas a oblongo-elípticas, rara vez orbiculares, 10-35 × 6-25 mm, base cuneada a oblicua, margen ondulado o crenulado, ápice agudo a obtuso, haz verde en ocasiones con tintes rojizos cerca de los márgenes, envés más claro que el haz; inflorescencias en la axila de la hoja mas pequeña del nudo, pedúnculos 5-20 mm de largo, por lo común más largos cerca de la base de los tallos, glandular pubescentes; involucro de brácteas ovadas, 5-6(7) × 4-5 $\mathrm{mm}$, color marrón a marrón amarillentas con tintes rojizos, ápice agudo a obtuso, vilosas; perianto blanco a lila, 3-5(6) $\mathrm{mm}$ de largo; estambres 4(-6), fusionados por debajo del ovario en un anillo corto; filamentos 3.5-4 mm de largo, del mismo color que el perianto; anteras globosas, 0.5-0.6 mm de diámetro, blancas o amarillas; ovario 0.5-0.6 mm de largo; estilo filiforme, 3-3.5 mm de largo, del mismo color que el perianto; estigma capitado, papiloso; antocarpo 3.5-4(5) $\mathrm{mm}$ de largo, márgenes profundamente dentados, dientes 5-8, alargados y agudos, encorvados hacia la cara cóncava, ésta con dos costillas de 6-7 dientes finos con glándulas apicales, cara convexa rugosa, costillas 3 , central 1 , marginales 2 , base truncada, ápice atenuado, color marrón claro a amarillento.

Distribución: desde el suroeste de Estados Unidos de América hasta el centro-oeste de Sudamérica (Spellenberg, 2003). En México se reporta para Aguascalientes, Chihuahua, Ciudad de México, Coahuila, Estado de México, Guanajuato, Guerrero, Hidalgo, Jalisco, Nuevo León, Oaxaca, Puebla, Querétaro, San Luis Potosí, Tamaulipas, Veracruz y Zacatecas. En Aguascalientes se distribuye en los municipios Aguascalientes, Asientos, Calvillo, El Llano, San Francisco de Los Romo y Tepezalá (Fig. 3).

Hábitat: matorral xerófilo y vegetación secundaria, en elevaciones de 1900-2200 m s.n.m.

Fenología: florece y fructifica durante todo el año, principalmente de finales de marzo a principios de octubre.

Ejemplares examinados: MÉXICO. Aguascalientes, municipio Aguascalientes, arroyo Paso Hondo, 18.III.1983, M. E. Siqueiros 2082 (HUAA); $1.5 \mathrm{~km}$ al E de Aguascalientes (Ojo de Palmitas), 23.IX.1993, M. de la Cerda 5851 (HUAA); a $2.5 \mathrm{~km}$ al NO de Calvillito, $21^{\circ} 48^{\prime} 18.6^{\prime \prime} \mathrm{N}, 102^{\circ} 10^{\prime} 14.5^{\prime \prime O}$, 28.VIII.2013, M. H. Sandoval 817 (HUAA); rancho El Refugio, $21^{\circ} 47^{\prime} 37.3^{\prime \prime} \mathrm{N}, 102^{\circ} 15^{\prime} 10.2^{\prime \prime O}$, 4.X.2013, M. H. Sando- 


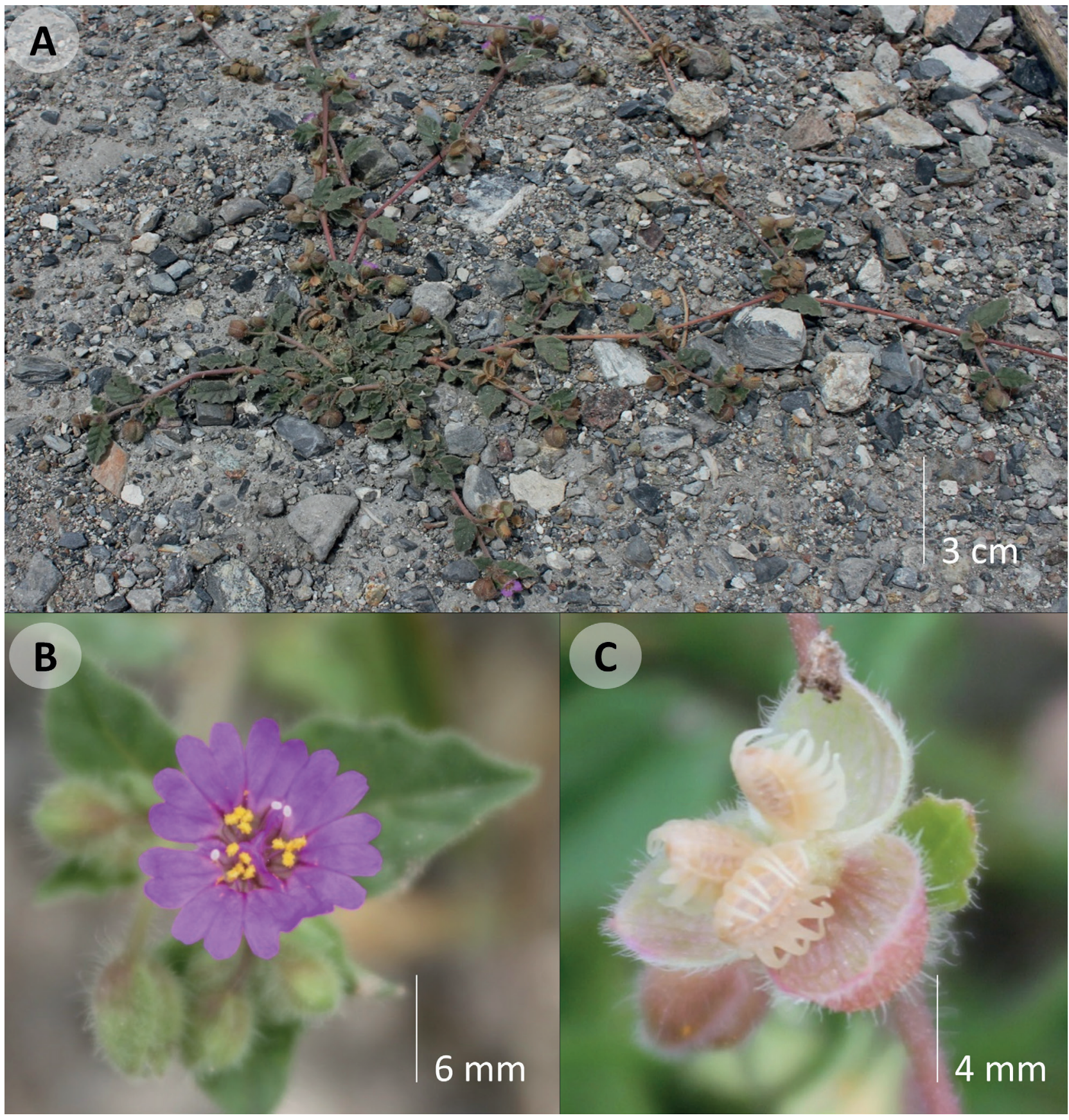

Figura 2: Allionia choisyi Standl. A. vista general; B. inflorescencia con tres flores simulando una sola en antesis; C. antocarpos.

val 871 (HUAA). Municipio Asientos, $2 \mathrm{~km}$ al SE de Asientos, $22^{\circ} 13^{\prime} 38.5^{\prime \prime} \mathrm{N}, 102^{\circ} 04^{\prime} 28.5^{\prime \prime O}, 3 . I V .2013$, M. H. Sandoval 544 (HUAA); $1.7 \mathrm{~km}$ al SE de El Tule, $22^{\circ} 01^{\prime} 58.9^{\prime \prime} \mathrm{N}, 102^{\circ} 05^{\prime} 51.0^{\prime \prime} \mathrm{O}$, 21.VIII.2013, M. H. Sandoval 792 (HUAA); $1 \mathrm{~km}$ al NO de Pino Suárez, $22^{\circ} 10^{\prime} 25.9^{\prime \prime} \mathrm{N}, 102^{\circ} 0614.9^{\prime \prime} \mathrm{O}, 21 . \mathrm{VIII.2013,} \mathrm{M.}$ H. Sandoval 793 (HUAA). Municipio Calvillo, 2 km al SE de Presa de los Serna, $21^{\circ} 48^{\prime} 02.7^{\prime \prime} \mathrm{N}, 102^{\circ} 49^{\prime} 13.9^{\prime \prime O}$, 6.IX.2013, M. H. Sandoval 843 (HUAA). Municipio El Llano, $1.7 \mathrm{~km}$ al
NE de El Tule, $21^{\circ} 54^{\prime} 45.4^{\prime \prime} \mathrm{N}, 101^{\circ} 55^{\prime} 06.4^{\prime \prime O}, 15 . X I .2012, M$. H. Sandoval 433 (HUAA); Barranca de La Mina a $6.7 \mathrm{~km}$ al NE de Palo Alto, $21^{\circ} 56^{\prime} 34.1^{\prime \prime} \mathrm{N}, 101^{\circ} 54^{\prime} 23.4^{\prime \prime O}, 17 . \mathrm{VII} .2013$, M. H. Sandoval 693 (HUAA). Municipio San Francisco de los Romo, $5 \mathrm{~km}$ al NE de Cañada Honda, 22 $02^{\prime} 24.0^{\prime \prime} \mathrm{N}$, $102^{\circ} 10^{\prime} 37.8^{\prime \prime O}$, 30.VIII.2012, M. E. Mendoza 837 (HUAA); $2 \mathrm{~km}$ al SE de San Francisco de los Romo, 4.VII.2013, $22^{\circ} 03^{\prime} 14.9^{\prime \prime} \mathrm{N}, 102^{\circ} 14^{\prime} 44.4^{\prime \prime O}$, M. H. Sandoval 677 
- Allionia choisyi

- Allionia incarnata

- Boerhavia anisophylla

- Boerhavia coccinea

$\triangle$ Boerhavia erecta

- Boerhavia gracillima

- Commicarpus scandens

- Cyphomeris gypsophiloides

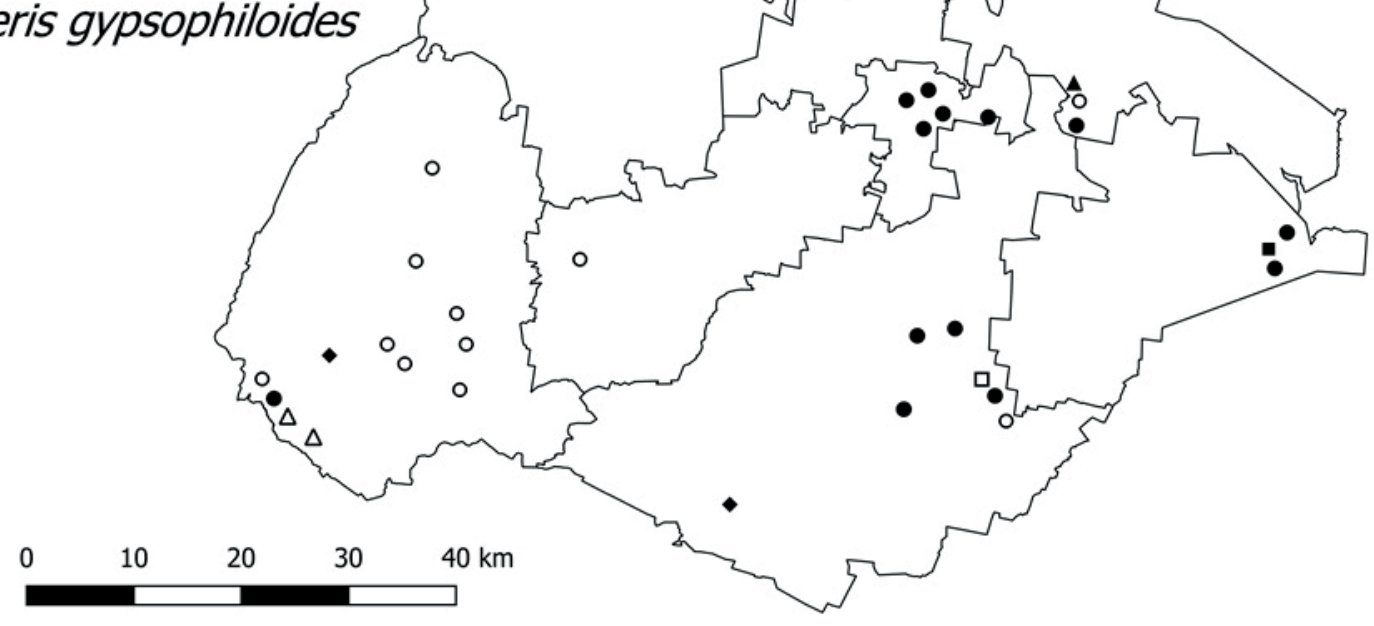

Figura 3: Distribución de las especies de los géneros Allionia L., Boerhavia L., Commicarpus Standl. y Cyphomeris Standl. en el estado de Aguascalientes, México.

(HUAA); $2 \mathrm{~km}$ al O de Borrotes, 4.VII.2013, 2202'12.3" $\mathrm{N}$, $102^{\circ} 13^{\prime} 29.4^{\prime \prime O}$, M. H. Sandoval 679 (HUAA); $1.5 \mathrm{~km}$ al NO de Borrotes, 22 $02^{\prime} 34.3^{\prime \prime} \mathrm{N}, 102^{\circ} 13^{\prime} 04.9^{\prime \prime} \mathrm{O}, 4 . \mathrm{VII} .2013, \mathrm{M}$. H. Sandoval 680 (HUAA); $3 \mathrm{~km}$ al E de San Francisco de los Romo, 22 $03^{\prime} 45.9^{\prime \prime} \mathrm{N}, 102^{\circ} 13^{\prime} 52.2^{\prime \prime} \mathrm{O}, 4 . \mathrm{VII} .2013$, M. H. Sandoval 682 (HUAA). Municipio Tepezalá, $2.7 \mathrm{~km}$ al SE de Tepezalá, $22^{\circ} 15^{\prime} 50.5^{\prime \prime} \mathrm{N}, 102^{\circ} 09^{\prime} 07.8^{\prime \prime O}, 10 . I V .2013, M$. E. Mendoza 502 (HUAA); arroyo Las Pilas, 22¹5'32.7"N, $102^{\circ} 10^{\prime} 18.3^{\prime \prime O}$, 8.XI.2012, M. H. Sandoval 343 (HUAA); arroyo Las Pilas, $1.3 \mathrm{~km}$ al NO de la Ex Hacienda Las Pilas, $22^{\circ} 15^{\prime} 43.5^{\prime \prime} \mathrm{N}, 102^{\circ} 10^{\prime} 32.4^{\prime \prime O}, 2 . \mathrm{VIII} .2013$, M. H. Sandoval $719 a$ (HUAA).
Allionia incarnata L., Syst. Nat. (ed. 10) 2: 890. 1759. TIPO: VENEZUELA. Mérida, Sucre, Las González - San José road, near the village of Las González, ca. $20 \mathrm{~km}$ Southwest of Mérida, 9-10.IX.1990, L. J. Dorry y L. C. Barnett 7674 (neotipo: US-01049571!; isoneotipos: NY, PORT, VEN, designado por Dorr y Wiersema, 2010). Fig. 4.

इWedelia incarnata (L.) Kuntze, Revis. Gen. PI. 1: 533. 1891. इWedeliella incarnata (L.) Cockerell, Torreya 9(8): 167. 1909.

Plantas perennes, herbáceas, pubescentes; tallos postrados a decumbentes, 7-100 cm de largo, vilosos cuando jóvenes, glabrescentes, comúnmente rojizos; pecíolo 


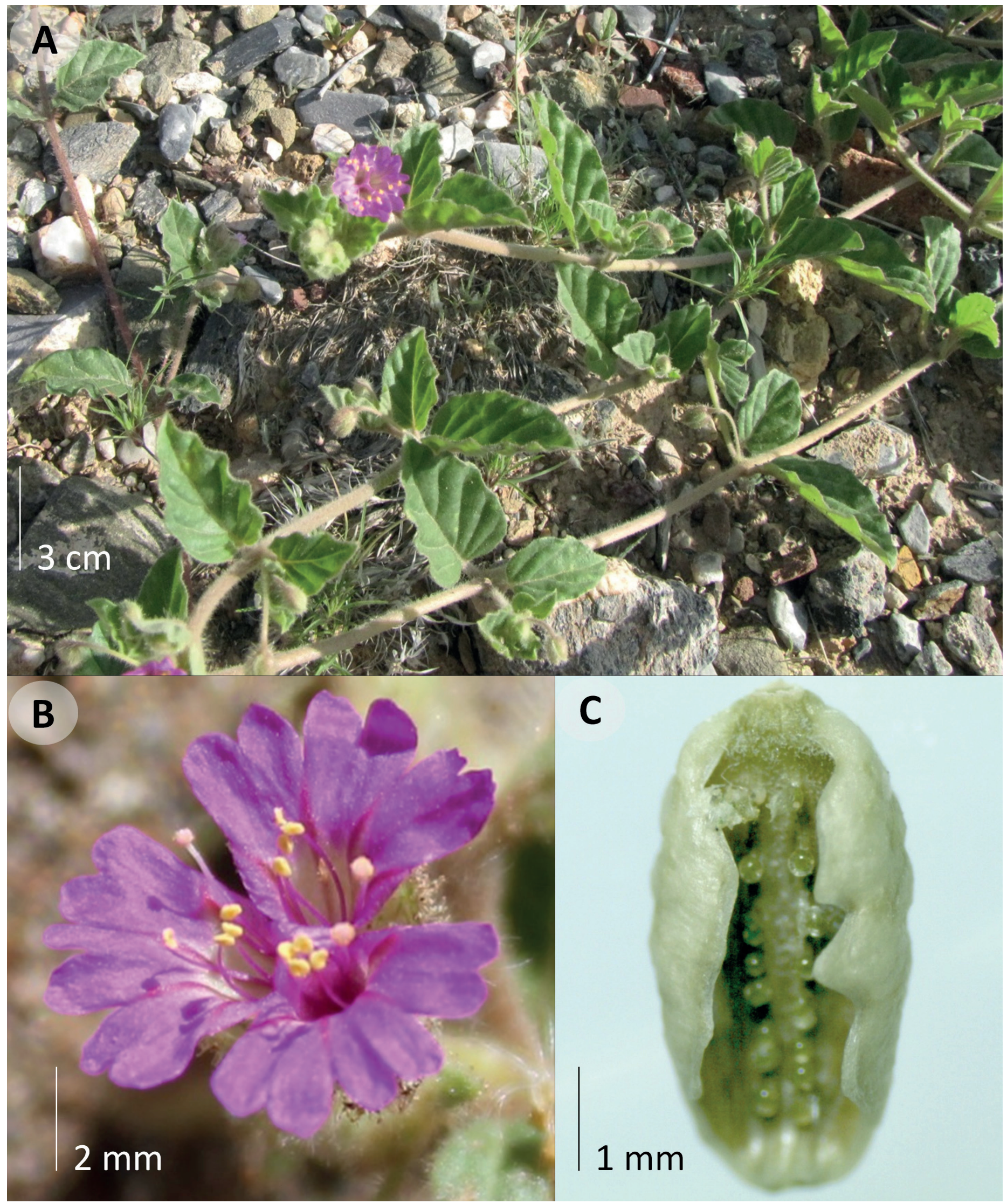

Figura 4: Allionia incarnata L. A. vista general; B. inflorescencia con tres flores simulando una sola durante la antesis; C. antocarpo. 
1-15(20) mm de largo, con pubescencia y color similar al de los tallos; láminas foliares ovadas a oblongo-elípticas, rara vez orbiculares, $1-3.5 \times 0.5-3 \mathrm{~cm}$, base cuneada a oblicua, margen ondulado o crenulado, ápice agudo a obtuso, haz verde en ocasiones con tintes rojizos cerca de los márgenes, envés más claro que el haz; inflorescencias en la axila de la hoja más pequeña del nudo, pedúnculos 5-20(23) mm de largo, por lo común más largos cerca de la base de los tallos, glandular pubescentes; involucro de brácteas ovadas, 4-5(5.5) × 3-3.5(4) mm, color marrón a marrón amarillentas con tintes rojizos, ápice obtuso a agudo, vilosas; perianto rosado a lila, 5-8(9) mm de largo; estambres 4(-6), fusionados por debajo del ovario en un anillo corto; filamentos 4-5 $\mathrm{mm}$ de largo, del mismo color que el perianto, anteras globosas, 0.5-0.6 $\mathrm{mm}$ de diámetro, blancas o amarillas; ovario 0.8-1 mm de largo, estilo filiforme, 5-6 mm de largo, del mismo color que el perianto, estigma capitado, papiloso; antocarpo 4-5 mm de largo, márgenes irregularmente ondulados a lisos, encorvados hacia la cara cóncava, ésta con dos costillas con 5-6(7) dientes finos con glándulas apicales; cara convexa rugosa, costillas 3 , central 1 , marginales 2 , base trunca, ápice atenuado, color marrón grisáceo a grisverdoso.

Distribución: desde Norteamérica a Sudamérica, incluyendo las Antillas (Spellenberg, 2003). En México se reporta en Aguascalientes, Chihuahua, Coahuila, Durango, Guanajuato, Hidalgo, Jalisco, Nuevo León, San Luis Potosí, Sonora, Tamaulipas y Zacatecas. En Aguascalientes se registra en los municipios Asientos y Tepezalá (Fig. 3).

Hábitat: matorral xerófilo, en elevaciones de 19002000 m s.n.m.

Fenología: florece y fructifica de agosto a noviembre.

Ejemplares examinados: MÉXICO. Aguascalientes, municipio Asientos, $3 \mathrm{~km}$ al $\mathrm{N}$ de El Llavero, $22^{\circ} 04^{\prime} 08.8^{\prime \prime} \mathrm{N}$, $102^{\circ} 05^{\prime} 59.5^{\prime \prime O}$, 6.IX.2012, M. H. Sandoval 104 (HUAA). Municipio Tepezalá, $4 \mathrm{~km}$ al E de Tepezalá ( $\mathrm{N}$ de la Loma el Corralillo), 11.IX.1980, M. de la Cerda y G. García 248 (HUAA); arroyo Las Pilas, $22^{\circ} 15^{\prime} 32.7^{\prime \prime} \mathrm{N}, 102^{\circ} 10^{\prime} 18.3^{\prime \prime O}$, 8.XI.2013, M. H. Sandoval 337 (HUAA); arroyo Las Pilas, $1.3 \mathrm{~km}$ al NO de Ex Hacienda Las Pilas, $22^{\circ} 15^{\prime} 43.5^{\prime \prime} \mathrm{N}, 102^{\circ} 10^{\prime} 32.4^{\prime \prime O}$, 2.VIII.2013, M. H. Sandoval 719 (HUAA).

Boerhavia L., Sp. PI. 1: 3. 1753. TIPO: Boerhavia erecta L.

Plantas anuales o perennes, herbáceas o subfrutescentes; tallos procumbentes, decumbentes, ascendentes o erectos, comunmente glandulares o con exudado víscido, inermes; hojas opuestas, pecioladas, subiguales; láminas foliares, membranosas o ligeramente suculentas, margen entero o sinuado, ápice obtuso, agudo o redondeado, por lo común discoloras; inflorescencias terminales o axilares, cimosas, umbeladas o subumbeladas; brácteas pequeñas, lineares a ovadas, deciduas o persistentes, libres, sin ocultar la base de la flor en la antesis, no acrescentes; flores actinomorfas, bisexuales, pediceladas; perianto membranáceo, campanulado o anchamente infundibuliforme, constreñido basalmente por encima del ovario, lóbulos 5 , emarginados; estambres 1-5, inclusos o exsertos, fusionados en la base; estilo extendiéndose un poco más allá de las anteras, estigma peltado; antocarpo de simetría radial, claviforme, u oblongo-claviforme, rígidamente coriáceo, glabro o pubescente, a menudo glandular, costillas (4)5, redondeadas, angulosas o aladas, surcos lisos o rugosos.

Género con cerca de 40 especies distribuidas en zonas cálidas y tropicales de todo el mundo (Spellenberg, 2003). Alrededor de 15 presentes en México. Para Aguascalientes se reportan cuatro.

Clave para especies de Boerhavia presentes en Aguascalientes

1a. Antocarpo glanduloso; hojas dispuestas a lo largo de todo el tallo .. 2

1b. Antocarpo liso; hojas dispuestas en las primeras $2 / 3$ partes de la planta 3

2a. Inflorescencias cimas cortas y densas que aparentan una umbella compacta o glomérulo con $\geq 10$ flores; perianto $\leq 2.5 \mathrm{~mm}$ de largo, color magenta

B. coccinea Mill.

2b. Inflorescencias cimas laxas con 1-3 flores; perianto $\geq 4 \mathrm{~mm}$ de largo, color rojo o anaranjado B. gracillima Heimerl

3a. Plantas anuales, herbáceas; perianto $\leq 2 \mathrm{~mm}$ de largo, 
color blanco o rosado; costillas del antocarpo agudas o crestadas; estambres 3 B. erecta $\mathrm{L}$.

3b. Plantas perennes, sufruticosas; perianto $\geq 5 \mathrm{~mm}$ de largo, color púrpura o lila; costillas del antocarpo redondeadas; estambres 5 B. anisophylla Torr.

Boerhavia anisophylla Torr., U.S. Mex. Bound. 2(1): 171. 1859. TIPO: ESTADOS UNIDOS DE AMÉRICA. Texas, Entrance of the Great Cañon of the Rio Grande, X.18501854, C. C. Parry y J. M. Bigelow 1135 (sintipo: CAS0027889!, US-00102942!). Fig. 5.

Plantas perennes, sufruticosas; tallos erectos o ascendentes, $15-50 \mathrm{~cm}$ de alto, puberulentos con tricomas glandulares y eglandulares; hojas dispuestas en las primeras 2/3 partes de la planta, sésiles, subsésiles o pecioladas; pecíolos 1-10 $\mathrm{mm}$ de largo, puberulentos con tricomas eglandulares; láminas ovadas, lanceoladas u oblongo elípticas, rara vez orbiculares, 6-25 × 3-15 mm, base trunca a redondeada, a veces cordada, margen entero, ondulado, comúnmente rojizo, ápice agudo, obtuso o redondeado, haz esparcidamente puberulenta con tricomas eglandulares, venación conspicua, color verde, en ocasiones con tonalidades rojizas o púrpura, envés glandular puberulento y glandular punteado, venas prominentes, glauco o más claro que el haz; inflorescencias axilares y terminales, dispuestas en la porción distal de los tallos, conjunto de cimas con 2-3(5) flores o flores solitarias; brácteas 3, subyacentes a cada flor, subuladas, $1-2 \times 0.5 \mathrm{~mm}$, margen escarioso y ciliado, ápice acuminado, color marrón, persistentes; flores subsésiles, pedicelo 0.3-2(4) mm de largo, con una bráctea basal similar a las de las flores; perianto infundibuliforme, 5-7 mm de largo, color lila a púrpura, lóbulos 5, emarginados; estambres 5, exsertos, filamentos (5)6-8 mm de largo, delgados, del mismo color que el perianto, anteras globosas, 0.5-0.6 mm de largo; estilo (6)7-8 mm de largo, estigma discoidal, liso; antocarpo claviforme, 2.5-3(3.5) mm de largo, crestas 5, redondeadas, surcos diminutamente papilosos, ápice redondeado a agudo, color verde a marrón grisáceo.

Distribución: desde Texas al centro de México (Spellenberg, 2003). En México se reporta para los estados de
Aguascalientes, Chihuahua, Coahuila, Durango, Nuevo León y Zacatecas. En Aguascalientes se localiza en los municipios Asientos, Tepezalá y El Llano (Fig. 3).

Hábitat: matorral xerófilo, en elevaciones de 20002300 m s.n.m.

Fenología: florece y fructifica de junio a noviembre.

Ejemplares examinados: MÉXICO. Aguascalientes, municipio Asientos, alrededores de la mina FRISCO, $22^{\circ} 13^{\prime} 47.8^{\prime \prime} \mathrm{N}, 102^{\circ} 07^{\prime} 21.4^{\prime \prime} \mathrm{O}, 13 . X .2012$, M. H. Sandoval 256 (HUAA). Municipio El Llano, $1.7 \mathrm{~km}$ al NE de El Tule, $21^{\circ} 54^{\prime} 45.4^{\prime \prime} \mathrm{N}, 101^{\circ} 55^{\prime} 06.4^{\prime \prime} \mathrm{O}, 15 . \mathrm{XI.2012,} \mathrm{M.} \mathrm{H.} \mathrm{San-}$ doval 436 (HUAA). Municipio Tepezalá, extremo NE de arroyo Hondo, 2209'6.8'N, 102³2'01"O, 27.VII.2007, G. García 5344 (HUAA); arroyo Las Pilas, 22¹5'32.7' N, 102¹0'18.3"O, 8.XI.2012, M. H. Sandoval 335 (HUAA); Cerro Camuero, 22¹4'03.6' N, 102¹0'45.5'O, 8.XI.2012, M. H. Sandoval 346 (HUAA); carretera Tepezalá - Puerto de la Concepción a $3 \mathrm{~km}$ al SE de Tepezalá, 22¹2'30.0' $\mathrm{N}$, $102^{\circ} 08^{\prime 24.2 " O, ~ 26 . V I .2013, ~ M . ~ H . ~ S a n d o v a l ~} 623$ (HUAA); $500 \mathrm{~m}$ al $\mathrm{E}$ de Puerto de la Concepción, 22²12'10.1' $\mathrm{N}$, $102^{\circ} 07^{\prime} 52.4^{\prime \prime O}$, 26.VI.2013, M. H. Sandoval 632 (HUAA); arroyo Las Pilas, $1.3 \mathrm{~km}$ al NO de Ex Hacienda Las Pilas, $22^{\circ} 15^{\prime} 43.5^{\prime \prime} \mathrm{N}, 102^{\circ} 10^{\prime} 32.4^{\prime \prime O}$, 2.VIII.2013, M. H. Sandoval 724 (HUAA); arroyo Las Pilas, 2 km al NO de la Ex Hacienda Las Pilas, $22^{\circ} 15^{\prime} 59.1^{\prime \prime} \mathrm{N}, 102^{\circ} 10^{\prime} 50.0^{\prime \prime} \mathrm{O}, 2$.VIII.2013, M. H. Sandoval 733 (HUAA).

Boerhavia coccinea Mill., Gard. Dict., (ed. 8) 4. 1768. TIPO: JAMAICA. Sin localidad, 1730, W. Houston s.n. (holotipo: BM-000993062!). Fig. 6.

= Boerhavia caribaea Jacq., Observ. Bot. 4: 5. 1771. TIPO: MARTINICA. Habitantem vidi in insularum Caribaearum ruderatis, muris, ad margines semitarum in apricis \& siccis. Lámina de N.J. Jacquin, basada en una planta proveniente de Martinica, Observ. Bot. 4: 5, tab. 84.1771 (lectotipo: designado por Whitehouse, 1996).

= Boerhavia viscosa Lag. \& Rodr., Anales Ci. Nat. 4: 256. 1801. TIPO: PERÚ. Sin localidad, 1778-88, H. Ruiz L. y J. A. Pavón s.n. (holotipo: G-00458383!). 


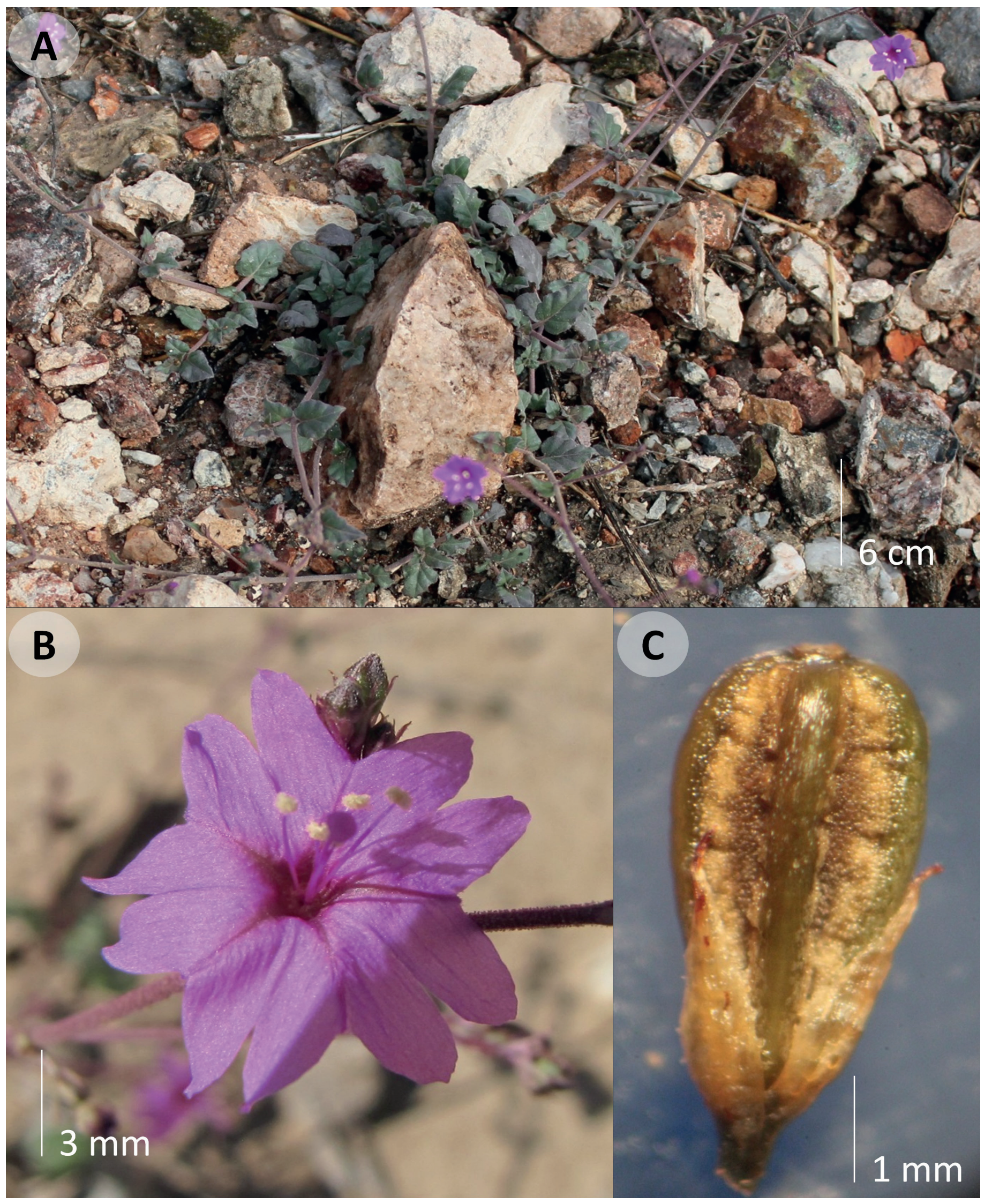

Figura 5: Boerhavia anisophylla Torr. A. vista general; B. flor; C. antocarpo con involucro persistente. 


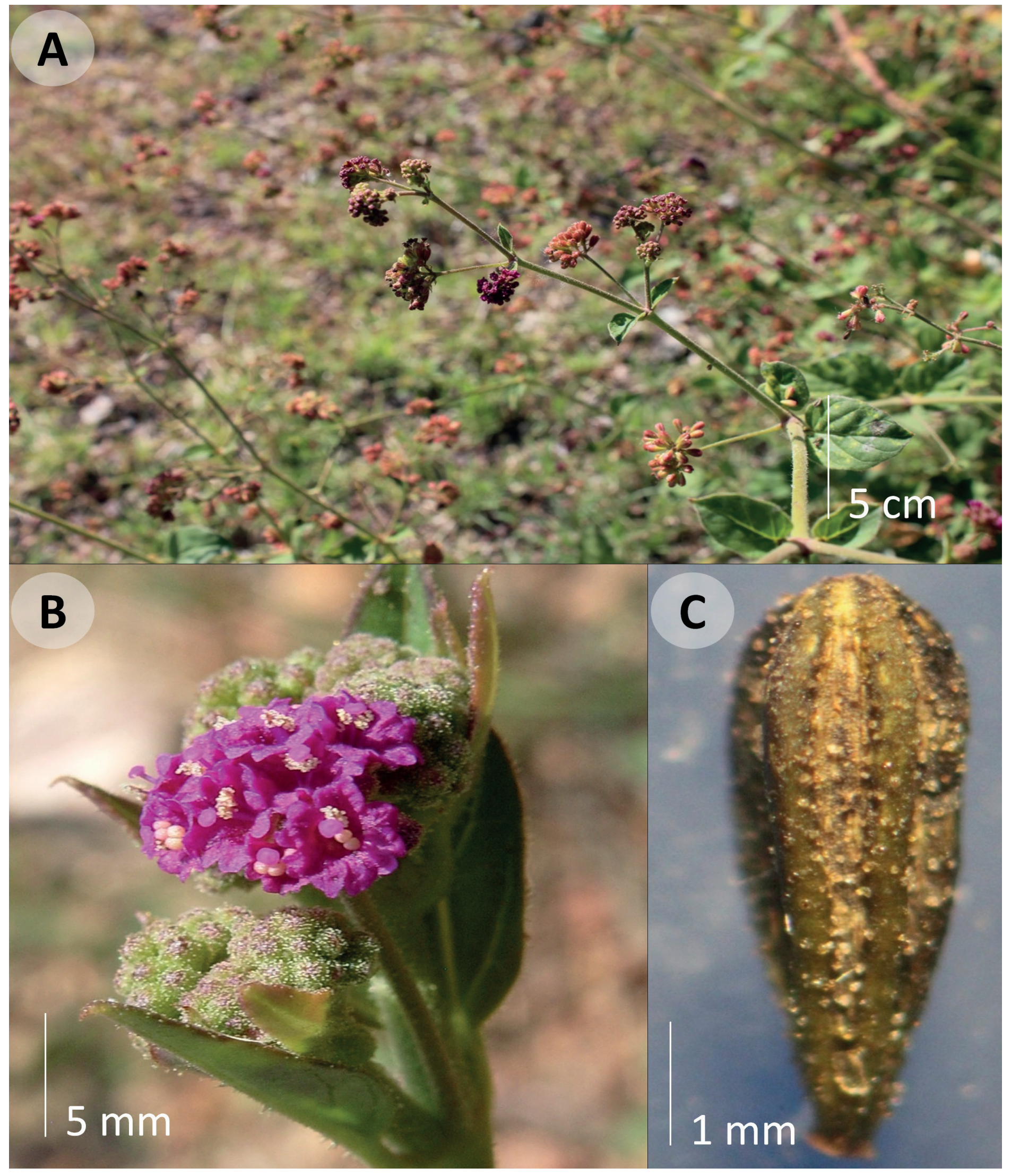

Figura 6: Boerhavia coccinea Mill. A. vista general; B. inflorescencia; C. antocarpo. 
Plantas perennes, herbáceas; tallos postrados a decumbentes, rara vez ascendentes, $20-150 \mathrm{~cm}$ de largo, densamente puberulentos con tricomas glandulares; hojas dispuestas a lo largo de todo el tallo, subiguales, las cercanas a la base pecioladas, distales sésiles, pecíolos 3-20(25) mm, puberulentos con tricomas glandulares; láminas foliares ovadas, lanceoladas u oblongo elípticas, rara vez orbiculares, 2-6 $\times 1.5-4.5 \mathrm{~cm}$, base trunca, oblicua o subcordada, margen ondulado a entero, glandular ciliado cerca de la base, ápice agudo a redondeado, haz densamente puberulenta con tricomas glandulares y eglandulares, color verde oscuro comunmente con tintes rojizos o púrpura cerca de los márgenes, densamente glandular puberulenta, envés glandular puberulento sobre las venas, glabro en el resto de su superficie, color glauco a verde pálido, en ocasiones con tintes rojizos; inflorescencias axilares y terminales, dispuestas en la porción distal de los tallos, cimas cortas y densas que aparentan una umbela compacta o glomérulo con $\geq 10$ flores; bráctea 1 , subyacente a cada flor, subulada, (0.5)1-1.3 × (0.2)0.5 mm, ápice acuminado, margen ciliado, decidua; flores subsésiles, pedicelos $\leq 0.3 \mathrm{~mm}$ de largo, perianto campanulado, 2-2.2(2.5) $\mathrm{mm}$ de largo, color magenta, lóbulos 5, ápice entero a levemente emarginado; estambres 3, ligeramente exsertos, filamentos 1-1.3 mm de largo, delgados, del mismo color que el perianto, anteras globosas, 0.2-0.3 mm de largo; estilo 1.5-1.7 mm de largo, del mismo color que el perianto, estigma discoidal, liso; antocarpo claviforme, 3-4 mm de largo, crestas 5, redondeadas, surcos más claros que las crestas, ápice redondeado, glandular puberulento, color verdoso a marrón.

Distribución: desde Estados Unidos de América a Centroamérica, introducida en África, Asia, Australia y Europa (Spellenberg, 2003). En México se reporta para los estados de Aguascalientes, Baja California, Baja California Sur, Chihuahua, Ciudad de México, Colima, Durango, Estado de México, Guanajuato, Guerrero, Hidalgo, Jalisco, Morelos, Nayarit, Nuevo León, Oaxaca, Puebla, Querétaro, Sinaloa, Sonora, Tamaulipas, Tlaxcala, Veracruz, Yucatán. En Aguascalientes se registra para los municipios Aguascalientes, Asientos, Calvillo, Cosío, Jesús María, Rincón de Romos, San José de Gracia y Tepezalá (Fig. 3).
Hábitat: matorral xerófilo, bosque tropical caducifolio, matorral subtropical y vegetación secundaria, en elevaciones de 1700-2100 m s.n.m.

Fenología: florece y fructifica durante todo el año.

Ejemplares examinados: MÉXICO. Aguascalientes, municipio Aguascalientes, a $7.2 \mathrm{~km}$ al NE del Instituto Tecnológico de El Llano, 214'02.1"N, 10209'38.2"O, 28.VIII.2013, M. H. Sandoval 803 (HUAA). Municipio Asientos, Presa El Llavero, $22^{\circ} 04^{\prime} 00.2^{\prime \prime} \mathrm{N}, 102^{\circ} 05^{\prime} 48.0^{\prime \prime O}$, 6.IX.2012, M. H. Sandoval 112 (HUAA). Municipio CalviIlo, Huerta El Chilarillo, arroyo Los Caballos, 2.X.1994, G.

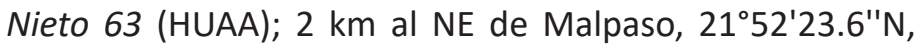
$102^{\circ} 39^{\prime} 22.4^{\prime \prime O}, 5 . V I .2013$, M. H. Sandoval 571 (HUAA); 500 $\mathrm{m}$ al SO de la cortina de la presa La Codorniz, $21^{\circ} 59^{\prime} 44.3^{\prime \prime} \mathrm{N}$, $102^{\circ} 40^{\prime} 43.6^{\prime \prime O}$, 29.IX.2012, M. H. Sandoval 171 (HUAA); arroyo Los Salates, Cañada Puente del Riego, 21 ${ }^{\circ} 50^{\prime} 50.1^{\prime \prime} \mathrm{N}$, $102^{\circ} 38^{\prime} 50.9^{\prime \prime O}, 29 . X I .2012$, M. H. Sandoval 489 (HUAA); 5 km de La Labor, carretera a Calvillo, 8.X.1982, M. E. Siqieiros 1955 (HUAA); O del poblado de Calvillo, 29.X.1993, M. de la Cerda 5093 (HUAA). Municipio Cosío, Tanque La Punta, al E del Poblado La Punta, 24.IX.2001, O. Rosales 2042 (HUAA). Municipio Jesús María, El Rinconcito, 23 km al O de Aguascalientes, 12.VIII.1996, M. de la Cerda 5613 (HUAA). Municipio Rincón de Romos, $3 \mathrm{~km}$ al SO de La punta, 22 $18^{\prime} 39^{\prime \prime} \mathrm{N}$, 102¹9'11"O, 7.VIII.2013, J. C. Sierra 849 (HUAA); 4 km al SO de Pabellón de Hidalgo, 25.VIII.1982, M. de la Cerda 1619 (HUAA). Municipio San José de Gracia, extremo N de la cabecera municipal del poblado de San José de Gracia, 19.VIII.1996, M. de la Cerda 5710 (HUAA, IEB); barranca al extremo NE de San José de Gracia, 2209'20.6"N, $102^{\circ} 24^{\prime} 35.3^{\prime \prime O}$, 14.VI.2013, M. H. Sandoval 595 (HUAA). Municipio Tepezalá, $2 \mathrm{~km}$ al SO de Tepezalá, $22^{\circ} 12^{\prime} 57.32^{\prime \prime} \mathrm{N}$, $102^{\circ} 11^{\prime} 16.96^{\prime \prime O}, 27 . V I I I .2010$, J. C. Sierra 142 (HUAA).

Boerhavia erecta L., Sp. PI. 1: 3. 1753. TIPO: MÉXICO. Veracruz, sin localidad, s.f., Anónimo s.n. (neotipo: LINN No. 9.1!, designado por Fawcett y Rendle, 1914). Fig. 7.

Plantas anuales, herbáceas; tallos erectos, 20-100 cm de alto, delgados, con zonas de exudado víscido, gla- 
bros o esparcidamente puberulentos cerca a los nudos, tricomas blanquecinos; hojas dispuestas en las primeras $2 / 3$ partes de la planta, proximales pecioladas, distales sésiles; pecíolos 3-15(20) mm de largo, glabros a esparcidamente pubescentes con tricomas similares a los de los tallos; láminas foliares ovadas a lanceoladas, 10-50(55) × 5-25 mm, margen entero $u$ ondulado, ciliado basalmente, general- mente rojizo, haz densamente puberulento, color verde, envés glabro o pubescente solo sobre las venas, glandular punteado, color verde grisáceo a glauco; inflorescencias axilares y terminales, dispuestas en la porción distal de los tallos, conjunto de cimas cortas que aparentan umbelas con 2-4(10) flores; brácteas (1)2-3, subuladas, (0.5)1-1.2 $\times 0.3 \mathrm{~mm}$, margen entero, ápice acuminado, color rojizo a

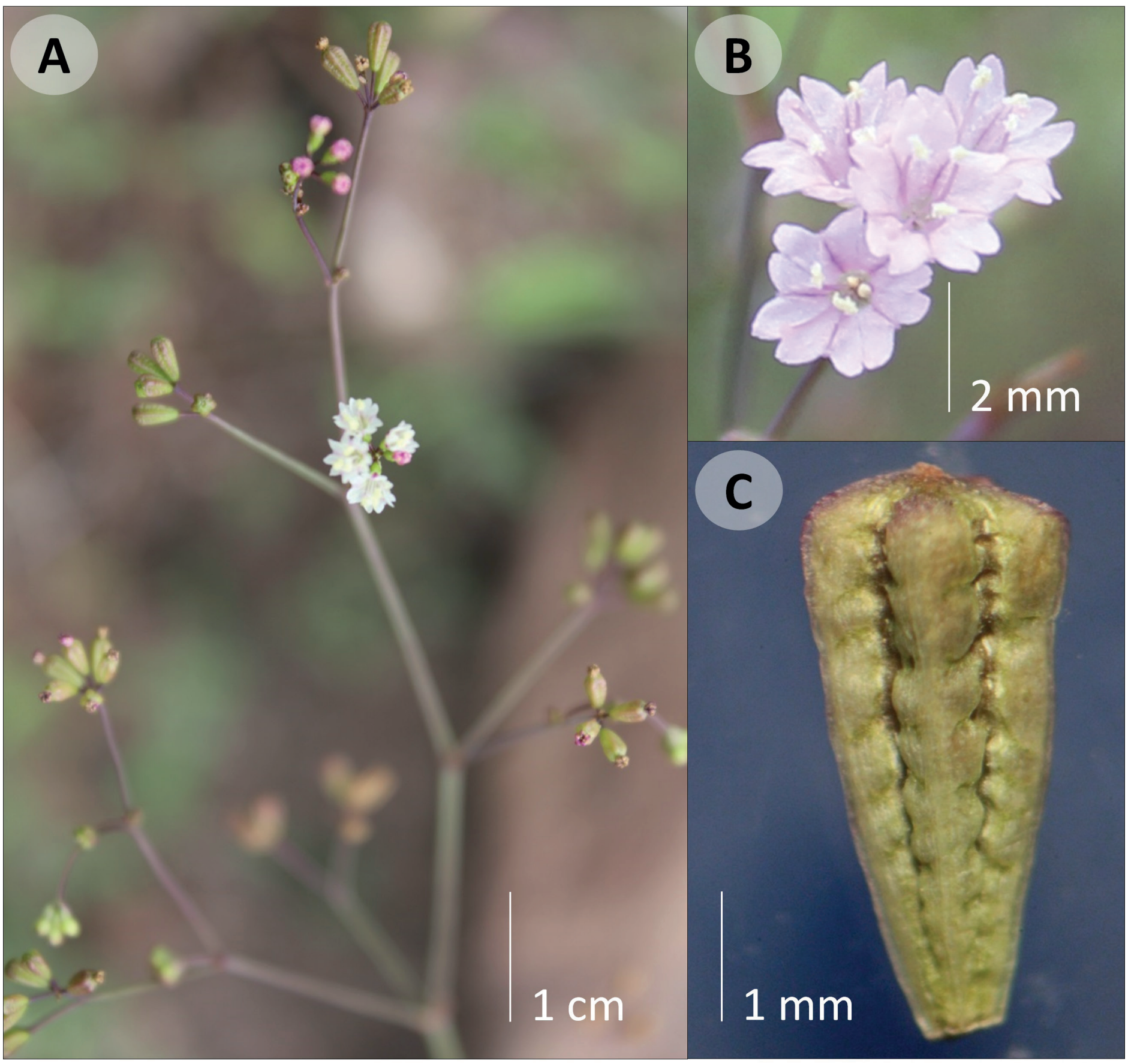

Figura 7: Boerhavia erecta L. A. vista general; B. inflorescencia; C. antocarpo. 
verde blanquecinas, caducas; pedicelos $0.2-1(1.5) \mathrm{mm}$ de largo, perianto campanulado, color blanco a rosado, 1-1.5 $\mathrm{mm}$ de largo, lóbulos 5, emarginados; estambres 3, ligeramente exsertos, filamentos 3-3.2 mm de largo, delgados, del mismo color que el perianto, anteras globosas, 0.5-0.6 $\mathrm{mm}$ de largo; estilo 1-2 mm de largo, del mismo color que el perianto, estigma discoidal, liso; antocarpo claviforme, 3-4 mm de largo, crestas 5, agudas, surcos irregulares, ápice redondeado a agudo, glabro, verde a grisáceo, usualmente con tonalidades rojizas.

Distribución: nativa de América tropical, introducida en zonas cálidas del mundo (Spellenberg, 2001; 2003). En México se reporta para Aguascalientes, Baja California, Baja California Sur, Campeche, Chiapas, Chihuahua, Ciudad de México, Coahuila, Colima, Durango, Estado de México, Guerrero, Hidalgo, Jalisco, Michoacán, Morelos, Nayarit, Nuevo León, Oaxaca, Puebla, Querétaro, Quintana Roo, San Luis Potosí, Sinaloa, Sonora, Tabasco, Tamaulipas, Veracruz, Yucatán y Zacatecas. En Aguascalientes se distribuye únicamente en el municipio Calvillo (Fig. 3).

Hábitat: matorral subtropical y bosque tropical caducifolio, en elevaciones de 1600 m s.n.m.

Fenología: florece y fructifica de junio a noviembre.

Ejemplares examinados: MÉXICO. Aguascalientes, municipio Calvillo, $2 \mathrm{~km}$ al SE de Presa de los Serna, $21^{\circ} 48^{\prime} 02.7^{\prime \prime} \mathrm{N}, 102^{\circ} 49^{\prime} 13.9^{\prime \prime O}, 6 . I X .2013$, M. H. Sandoval 842 (HUAA); $2 \mathrm{~km}$ al S de Jáltiche de Arriba, $21^{\circ} 45^{\prime} 19.3^{\prime \prime} \mathrm{N}$, $102^{\circ} 47^{\prime} 36.7^{\prime \prime O}$, 11.IX.2013, M. H. Sandoval 855 (HUAA).

Boerhavia gracillima Heimerl, Bot. Jahrb. Syst. 11(1): 8187. 1889. TIPO: MÉXICO. Chihuahua, rocky hills near Chihuahua, 15.VIII.1885, C. G. Pringle 665 (lectotipo: WU-0033299!; isolectotipo: GOET-008279! designado por Standley, 1911). Fig. 8.

= Boerhavia gracillima subsp. decalvata Heimerl ex Standl., Contr. U.S. Natl. Herb. 12(8): 386. 1909. TIPO: ESTADOS UNIDOS DE AMÉRICA. Texas, Bone Spring, VI.1883, V. Havard 59 (holotipo: US-00102953!).
Plantas perennes, herbáceas, muy ramificadas; tallos postrados, decumbentes o ascendentes, $20-100 \mathrm{~cm}$ de largo, glabros a esparcidamente puberulentos con tricomas glandulares y eglandulares; hojas dispuestas principalmente en la mitad inferior de los tallos, subiguales, proximales pecioladas, distales sésiles; pecíolos 5-15 mm de largo, pubescencia similar a la de los tallos; láminas foliares ovadas a lanceoladas u oblongo elípticas, rara vez orbiculares, 10-34(40) $\times(4) 7$ 25(30) mm, base cuneada a trunca, en ocasiones cordada, margen entero a ligeramente ondulado, ciliado basalmente, ápice agudo a obtuso, haz glabra a escasamente puberulenta, color verde, en ocasiones con tonalidades rojizas cerca de los márgenes; inflorescencias axilares y terminales, dispuestas en la porción distal de los tallos, conjunto de cimas laxas con 1-3 flores; brácteas 1-3, subyacentes a cada flor, linearlanceoladas, (0.5)1-1.3 × 0.2-0.3(0.5) mm, margen ciliado, ápice acuminado, caducas; flores pediceladas, pedicelos delgados, 5-10 mm de largo, con una bráctea basal similar a las de las flores; perianto campanulado, 4-5(6) mm de largo, color rojo a anaranjado, lóbulos 5, ápice emarginado; estambres (2)3(5), exsertos, filamentos 4-5 mm de largo, delgados, del mismo color que el perianto, anteras globosas, 0.3-0.4 $\mathrm{mm}$ de largo; estilo 3.7-4 mm de largo, estigma discoideo a subgloboso, liso; antocarpo claviforme, 3.5-4 mm de largo, crestas 5 , redondeadas, surcos más claros que las crestas, ápice redondeado, glandular puberulento, color marrón.

Distrubución: desde el sur de Estados Unidos de América al sur de México. En México se ha reportado para Aguascalientes, Baja California, Baja California Sur, Chihuahua, Coahuila, Durango, Guanajuato, Hidalgo, Jalisco, Michoacán, Nuevo León, Puebla, Querétaro, San Luis Potosí, Sonora, Sinaloa, Tamaulipas y Zacatecas. En Aguascalientes se localiza en los municipios Aguascalientes, Asientos, Cosío y Tepezalá (Fig. 3).

Hábitat: matorral xerófilo y pastizal, en elevaciones de 1900-2100 m s.n.m.

Fenología: florece y fructifica de junio a noviembre.

Ejemplares examinados: MÉXICO. Aguascalientes, municipio Aguascalientes, a $2.5 \mathrm{~km}$ al NO de Calvillito, 


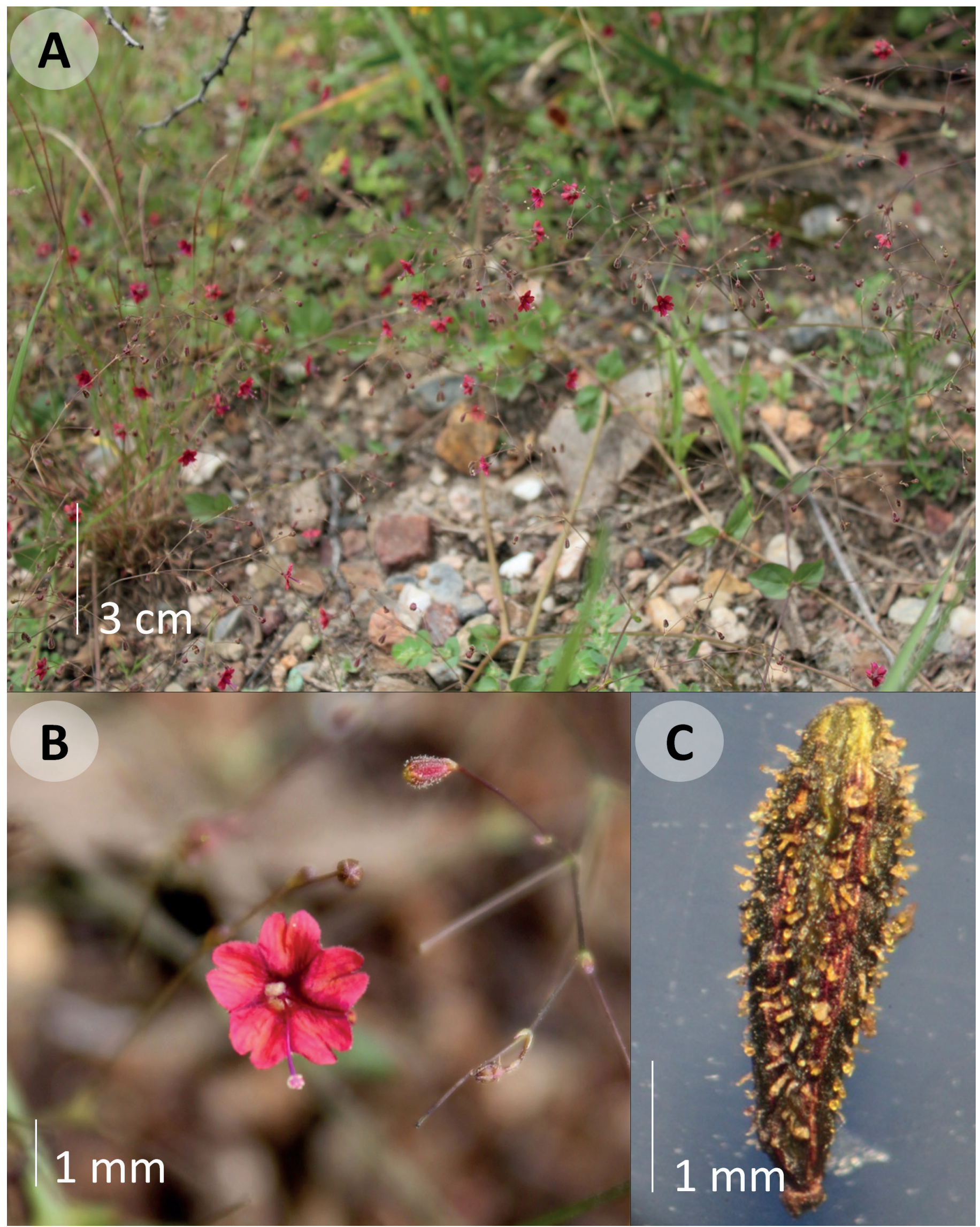

Figura 8: Boerhavia gracillima Heimerl. A. vista general; B. flor; C. antocarpo. 
$21^{\circ} 48^{\prime} 18.6^{\prime \prime} \mathrm{N}, 102^{\circ} 10^{\prime} 14.5^{\prime \prime O}$, 28.VIII.2013, M. H. Sandoval 814 (HUAA). Municipio Asientos, 1 km al NO de Pino Suárez, 21.VIII.2013, 22¹0'25.9"N, 102 06'14.9"O, M. H. Sandoval 795 (HUAA). Municipio Cosío, cerro Mesa Verde al O del poblado La Punta, 24.IX.2001, O. Rosales 2017 (HUAA). Municipio Tepezalá, arroyo Las Pilas, $22^{\circ} 15^{\prime} 32.7^{\prime \prime} \mathrm{N}, 102^{\circ} 10^{\prime} 18.3^{\prime \prime} \mathrm{O}$, 8.XI.2012, M. H. Sandoval 339 (HUAA); arroyo Las Pilas, 1.3 km al NO de Ex Hacienda Las Pilas, $22^{\circ} 15^{\prime} 43.5^{\prime \prime} \mathrm{N}, 102^{\circ} 10^{\prime} 32.4^{\prime \prime O}$, 2.VIII.2013, M. H. Sandoval 725 (HUAA); arroyo Las Pilas, 2 km al NO de la Ex Hacienda Las Pilas, 2.VIII.2013, 22 $15^{\circ} 59.1^{\prime \prime} \mathrm{N}$, $102^{\circ} 10^{\prime} 50.0^{\prime \prime O}$, M. H. Sandoval 730 (HUAA).

Commicarpus Standl., Contr. U.S. Natl. Herb. 12: 373. 1909. TIPO: Commicarpus scandens (L.) Standl.

Plantas perennes, sufruticosas o arbustivas; tallos erectos, ascendentes o decumbentes, sostenidos por vegetación vecina, muy ramificados, a menudo aparentando ser dicotómicos, inermes; hojas opuestas, subiguales a iguales, enteras, pecioladas, membranosas, glabras o pubescentes, más o menos concoloras en ambas caras; inflorescencias axilares o terminales, pedunculadas, capitadas, umbeliformes o verticiladas, con brácteas pequeñas, deciduas, lineares a ovadas, pubescentes o glabras, libres, una en la base de cada pedicelo, no acrescentes; flores actinomorfas, bisexuales, pediceladas, casmógamas, más o menos vistosas; perianto membranáceo, cortamente infundibuliforme o campanulado, constreñido basalmente por encima del ovario; estambres 2-6, exsertos, unidos en la base; estilo exserto, estigma peltado; antocarpo de simetría radial, angosta o anchamente claviforme, a veces algo curvado, rígidamente coriáceo, glabro o pubescente, con 10 costillas conspicuas o estrias poco evidentes, llevando grandes glándulas verrucosas distribuidas más densamente en la porción apical; semilla de testa delgada y adherente al fruto.

Género con alrededor de 30 especies distribuidas en América, Asia, Europa, Australia y África. Cuatro especies reportadas para Mexico (Harriman, 1999), solo una en el estado de Aguascalientes.

Commicarpus scandens (L.) Standl., Contr. U.S. Natl. Herb. 12(8): 373. 1909. Fig. 9.
三 Boerhavia scandens L., Sp. PI. 1: 3. 1753. TIPO: JAMAICA. Lámina de L. Plukenet, Phytographia pt. 3, tab. 226, f. 7. 1692 (lectotipo: designado por Kellogg, 1988).

Plantas perennes, por lo común arbustivas; tallos ascendentes, con frecuencia postrados sobre vegetación vecina, 0.7-1.2(2) $\mathrm{m}$ de alto, glabros a escasamente puberulentos, distalmente herbáceos y a veces rojizos, tornándose leñosos hacia la base, corteza grisácea y fisurada; hojas generalmente subiguales, pecíolos 3-25 mm de largo, con una línea longitudinal de tricomas cortos; láminas foliares cordadas a deltoides, $10-50 \times 5-40 \mathrm{~mm}$, base cordada a trunca, margen entero a ligeramente ondulado, en ocasiones rojizo, ápice agudo o acuminado, verdes; inflorescencias en forma de umbelas, 7-10 flores, pedúnculos 2-5.5 cm de largo, glabros; brácteas 5 , subyacentes a cada umbela antes de la antesis, angostamente lanceoladas, 2-2.5 × 0.5-1 mm, margen ciliado, ápice agudo, glabras o puberulentas sobre la vena media, deciduas; flores con pedicelos delgados, 7-11 mm de largo, glabros; perianto campanulado, (3)4-4.5 mm de largo, verde amarillento o blanquecino, lóbulos 5, emarginados; estambres 2, exsertos, filamentos delgados, 6-7 mm de largo, anteras globosas, 0.6-0.7 mm de largo; estilo filiforme, ligeramente más largo que los estambres, 7-7.5 mm de largo, estigma discoidal, liso, mas oscuro que el estilo; antocarpo claviforme, alargado, 1-1.5(2) cm de largo, estrechándose hacia la base, ápice redondeado a trunco, costillas poco visibles, con glándulas verrugosas prominentes esparcidas principalmente en el ápice, color verde a marrón.

Distribución: desde Norteamérica a Sudamérica, incluyendo las Antillas (Harriman, 1999; Spellenberg, 2003). En México se reporta para Aguascalientes, Baja California, Baja California Sur, Campeche, Chiapas, Chihuahua, Coahuila, Colima, Durango, Estado de México, Guanajuato, Hidalgo, Jalisco, Michoacán, Morelos, Oaxaca, Puebla, Querétaro, San Luis Potosí, Sinaloa, Sonora, Tamaulipas, Veracruz, Yucatán y Zacatecas. Se registra por primera vez para Aguascalientes en el presente trabajo, en los municipios Aguascalientes y Calvillo (Fig. 3).

Hábitat: matorral subtropical, matorral xerófilo y bosque de galería, en elevaciones de 1500-1900 m s.n.m. 


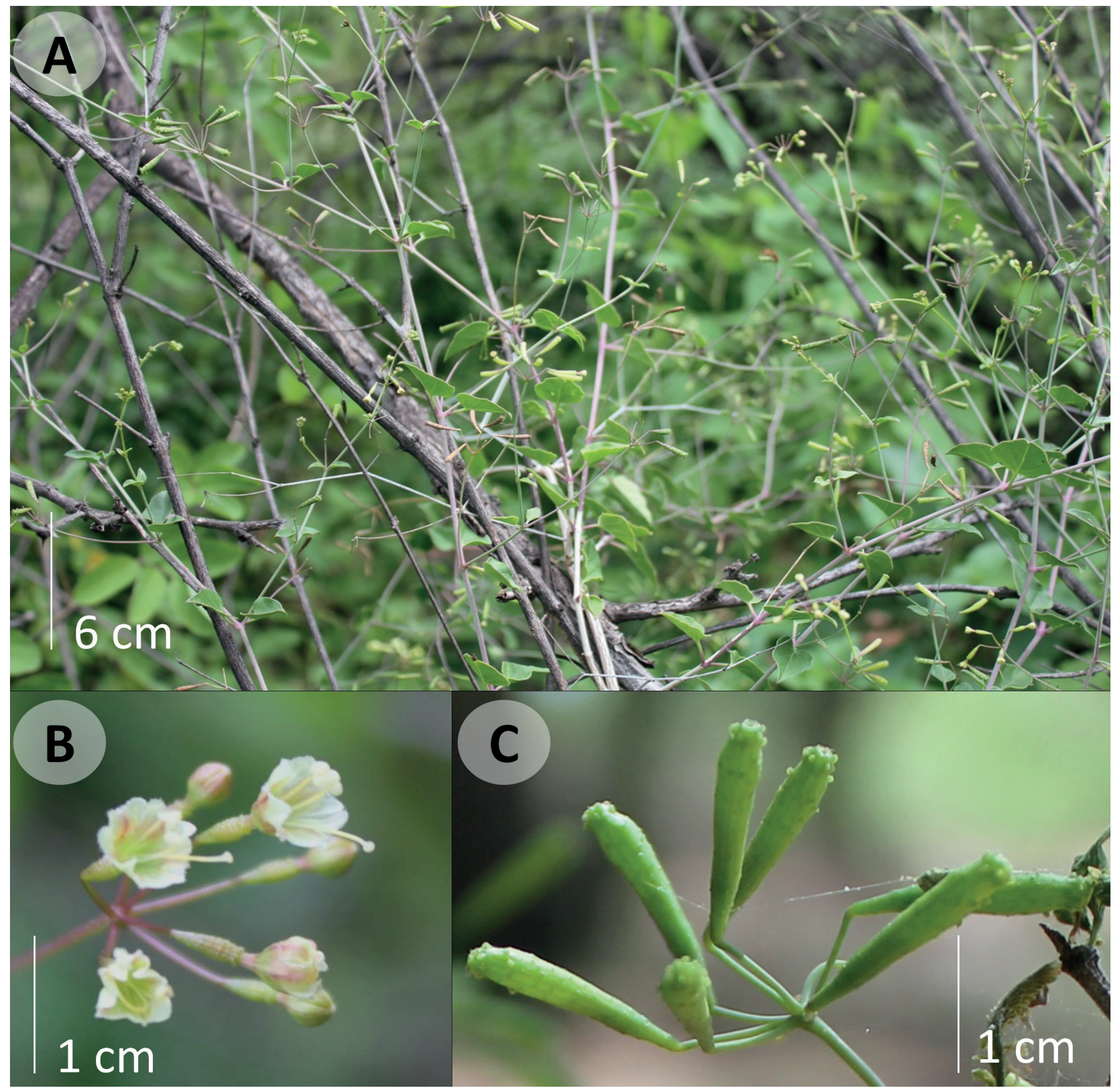

Figura 9: Commicarpus scandens (L.) Standl. A. vista general; B. inflorescencia; C. antocarpos.

Fenología: florece y fructifica de junio a noviembre.

Ejemplares examinados: MÉXICO. Aguascalientes, municipio Aguascalientes, $370 \mathrm{~m}$ al SE de San Pedro Cieneguilla, $21^{\circ} 42^{\prime} 47.1^{\prime \prime N}, 102^{\circ} 24^{\prime} 33.8^{\prime \prime O}$, 4.IV.2014, M. H. Sandoval 942 (HUAA); rancho El Refugio, $21^{\circ} 47^{\prime} 37.3^{\prime \prime} \mathrm{N}, 102^{\circ} 15^{\prime} 10.2^{\prime \prime O}$, 4.X.2013, M. H. Sandoval 872 (HUAA). Municipio Calvillo,
$2 \mathrm{~km}$ al SE de Presa de los Serna, 6.IX.2013, 21 $48^{\prime} 02.7^{\prime \prime} \mathrm{N}$, $102^{\circ} 49^{\prime} 13.9^{\prime \prime O}$, M. H. Sandoval 845 (HUAA); Las Pilas, 2150'14.6"N, 10246'14.6"O, 16.V.2014, M. H. Sandoval 951 (HUAA).

Cyphomeris Standl., Contr. U.S. Natl. Herb. 13: 428. 1911. TIPO: Cyphomeris gypsophiloides (M. Martens \& Galeotti) Standl. 
Plantas perennes, herbáceas o sufruticosas; tallos erectos, ascendentes, rastreros o postrados en vegetación vecina, inermes, cada entrenudo por lo general con un anillo glutinoso; hojas opuestas, subiguales, enteras a onduladas, sésiles o pecioladas, láminas foliares subcrasas o membranosas, el haz más pálido que el envés; inflorescencias en racimos laxos, terminales o axilares, pedunculados; brácteas presentes, pequeñas, subuladas a ovado-lanceoladas, libres, no acrescentes, caducas; flores actinomorfas o ligeramente zigomorfas, bisexuales, pediceladas, casmógamas o cleistógamas; perianto de las flores casmógamas infundibuliforme, constreñido basalmente por encima del ovario, la parte superior decidua en fruto; estambres 5 , a veces menos en flores cleistógamas, exsertos; filamentos unidos en la base; estilo exserto, estigma capitado; antocarpo claviforme, de simetría bilateral, giboso, rígidamente coriáceo, glabro, provisto de 8-10 costillas redondeadas poco prominentes, pericarpio delgado, papiráceo.

Género con dos especies distribuidas en Estados Unidos de América y México (Spellenberg, 2003), solo una reportada para Aguascalientes.

\section{Cyphomeris gypsophiloides (M. Martens \& Galeotti)} Standl., Contr. U.S. Natl. Herb. 13(11): 428. 1911. Fig. 10.

इ Lindenia gypsophiloides M. Martens \& Galeotti, Bull. Acad. Roy. Sci. Bruxelles 10(1): 358. 1843. TIPO: MÉXICO. Puebla, dans les plaines á mimosées et á cactées de Tehuacán de las Granadas, VIII.1840, H. G. Galeotti 577 (holotipo: BR-0000005230372!).

इ Boerhavia gypsophiloides (M. Martens \& Galeotti) J.M. Coult., Contr. U.S. Natl. Herb. 2(3): 354. 1894.

Plantas perennes, sufruticosas o herbáceas; tallos erectos o ascendentes, $20-80 \mathrm{~cm}$ de alto, ramificados principalmente en la base, glabros, con anillos de exudado glutinoso; hojas sésiles a subsésiles, reduciéndose de tamaño hacia el ápice, pecíolo $\leq 1 \mathrm{~mm}$ de largo; láminas foliares lineares a linear-elípticas, de 2-9 $0.2-0.6 \mathrm{~cm}$, base atenuada, margen entero, ápice agudo a obtuso; inflorescencias racimos laxos de flores alternas, terminales o axilares, pedúnculos 10-16 cm de largo, racimos 10-15(18) cm de largo; bráctea 1 subyacente a cada pedicelo, subulada a ovado- lanceolada, 4-5 × 0.5-1 mm, translúcida, con tintes rojizos o púrpura, margen ciliado, ápice acuminado; pedicelos 0.51(2) $\mathrm{mm}$; perianto infundibuliforme, (6)8-10 mm de largo, púrpura, lóbulos 5, levemente emarginados; estambres 5, exsertos, filamentos 13-15(17) $\mathrm{mm}$ de largo, del mismo color que el perianto, anteras globosas, 6-8 mm de largo; estilo filiforme, 15-16 mm de largo, del mismo color que el perianto; antocarpo 5-8(10) $\mathrm{mm}$ de largo, giboso ventralmente, costillas poco prominentes en ocasiones tuberculadas, verde amarillentos o verde con tonalidades púrpura.

Distribución: desde el suroeste de Estados Unidos de América a México (Spellenberg, 2003). Para México se reporta en Aguascalientes, Chihuahua, Coahuila, Durango, Hidalgo, Nuevo León, Puebla, Querétaro, San Luis Potosí y Tamaulipas. En Aguascalientes se localiza únicamente en el municipio Asientos (Fig. 3).

Hábitat: matorral xerófilo, en elevaciones de 22002300 m s.n.m.

Fenología: florece y fructifica de junio a noviembre.

Ejemplares examinados: MÉXICO. Aguascalientes, municipio Asientos, ladera NO del Cerro Altamira, 16.X.2009, J. Martínez 1485 (HUAA); $1.8 \mathrm{~km}$ al SE de Puerto de la Concepción, $22^{\circ} 11^{\prime} 21.7^{\prime \prime} \mathrm{N}, 102^{\circ} 07^{\prime} 21.3^{\prime \prime O}$, 21.VIII.2013, M. H. Sandoval 797 (HUAA).

Mirabilis L., Sp. PI. 1: 177. 1753; Gen. PI. ed. 5, 82. 1754. TIPO: Mirabilis jalapa L.

Plantas perennes, herbáceas, a veces sufruticosas, glabras o pubescentes con tricomas simples o glandulosos; tallos decumbentes a erectos, ramificados, inermes; hojas opuestas, membranosas a ligeramente suculentas, iguales a subiguales, sésiles o pecioladas, margen entero, sinuado o crespo, por lo general concoloras en ambas caras, rara vez más pálidas en el envés; inflorescencias terminales o axilares, glomérulos, 1-3(6) flores de antesis no simultánea rodeadas por un involucro, pedunculadas a subsésiles, dispuestas distalmente en sinflorescencias cimosas cortas o muy ramificadas, cuando axilares por lo común involu- 


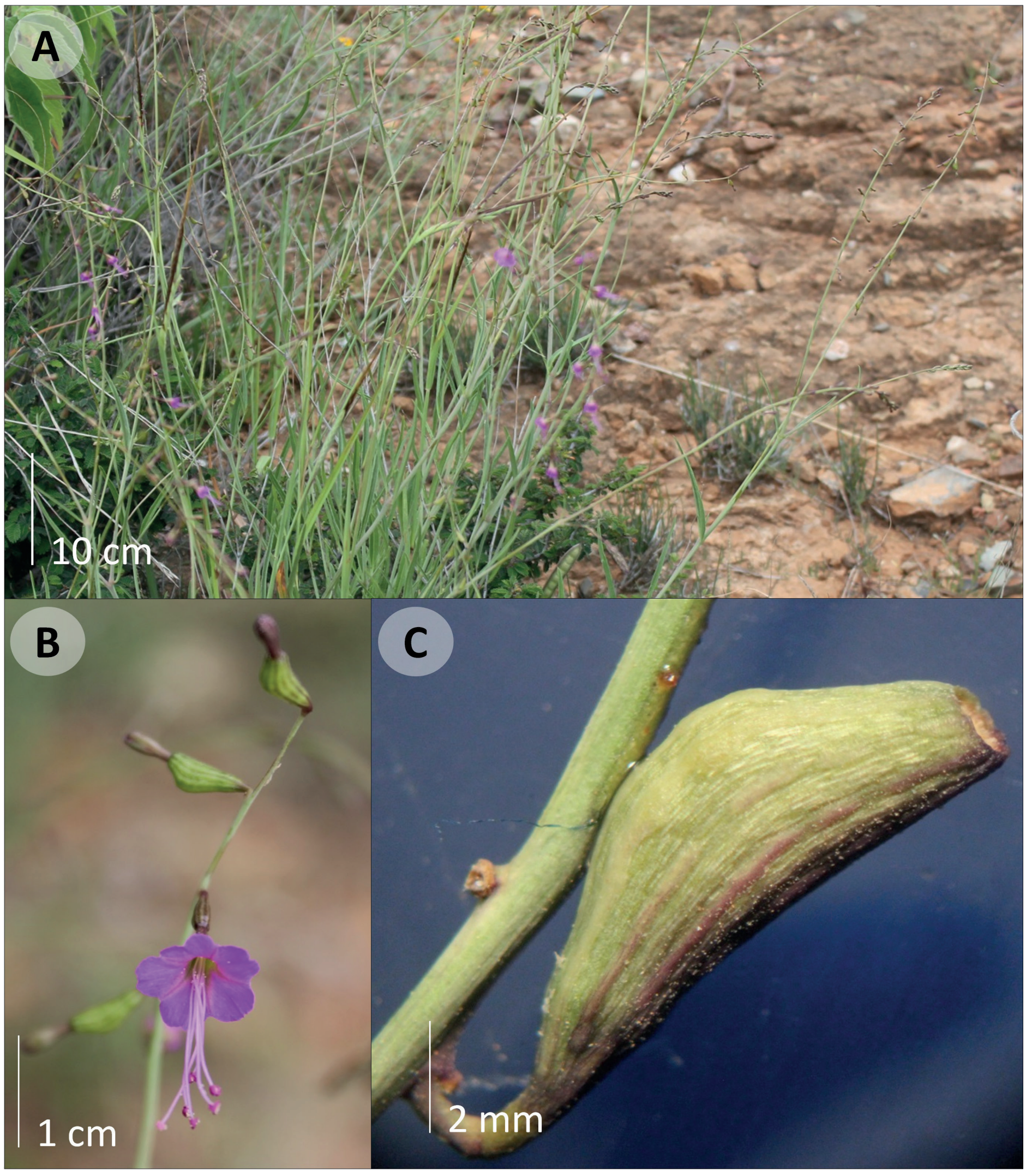

Figura 10: Cyphomeris gypsophiloides (M. Martens \& Galeotti) Standl. A. vista general; B. inflorescencia; C. antocarpo. 
cros solitarios; involucro 5 brácteas visibles, persistentes, fusionadas desde $1 / 2$ hasta toda su longitud, acrescentes, ocultando la base del perianto en la antesis y en ocasiones extendido y/o rotáceo en fruto; flores actinomorfas, bisexuales, sésiles o subsésiles, vistosas; perianto membranáceo, campanulado a largamente infundibuliforme, constreñido basalmente por encima del ovario; estambres 3-6, exsertos, unidos en la base; estilo exserto, excediendo ligeramente los estambres, estigma capitado; antocarpo de simetría radial, obovoide, elipsoide, cilíndrico o subgloboso, glabro o pubescente, provisto de 5 costillas longitudinales, prominentes o no, a veces cubierto por tubérculos mucilaginosos al hidratarse.

Género con 60 especies distribuidas en zonas cálidas de América y sólo una especie nativa de Asia (Spellenberg, 2003). Treinta y tres especies reportadas para México. Siete presentes en Aguascalientes.

Algunos autores se refieren a las inflorescencias de este género como el conjunto de involucros con flores, en el presente trabajo se considera a las inflorescencias como el conjunto de flores sésiles o subsésiles rodeadas por el involucro, y al conjunto de inflorescencias como sinflorescencias con base en Weberling (1985).

Clave para especies de Mirabilis presentes en Aguascalientes

1a. Perianto $\geq 30 \mathrm{~mm}$ de longitud 2

1b. Perianto $\leq 20 \mathrm{~mm}$ de longitud 3

2a. Tallos glabros a esparcidamente pubescentes con tricomas eglandulares y septados; tubo del perianto $\leq 50$ $\mathrm{mm}$ de largo M. jalapa L.

2b. Tallos glandular pubescentes; tubo del perianto de $\geq 60 \mathrm{~mm}$ de largo M. longiflora $\mathrm{L}$.

3a. Flores 3 por involucro; antocarpo cubierto por tricomas blanquecinos .. 4

3b. Flores 1 por involucro; antocarpo cubierto por tubérculos irregulares, translúcidos y mucilaginosos al hidratarse

4a. Láminas foliares lineares ... M. linearis (Pursh) Heimerl

4b. Láminas foliares oblongo elípticas a lanceoladas M. agreggata (Ortega) Cav.

5a. Láminas foliares de base cordada, densa a esparcidamente glandular pubescentes 5b. Láminas foliares de base truncada a cuneada, rara vez subcordada, glabras a esparcidamente puberulentas con tricomas eglandulares

M. glabrifolia (Ortega) I.M. Johnst.

Mirabilis aggregata (Ortega) Cav., Icon. 5: 22. 1799. Fig. 11.

इCalyxhymenia aggregata Ortega, Nov. Rar. PI. 81. 1798. TIPO: MÉXICO. Localidad no definida, ilustración basada en un ejemplar cultivado en el Real Jardín Botánico de Madrid de semillas provenientes de Nueva España enviadas por M. Sessé, s.f., M. Sessé s.n. (lectotipo aquí designado: Lámina 11 de Novarum, aut Rariorum Plantarum Horti Reg. Botan. Matrit. Descriptionum Decades Tab. 11. 1798).

三 Oxybaphus aggregatus (Ortega) Vahl, Enum. PI. 2: 41. 1806.

इ Allionia aggregata (Ortega) Spreng., Syst. 1: 384. 1825.

Plantas perennes, herbáceas; tallos erectos a ascendentes, $30-70 \mathrm{~cm}$ de alto, color verde intenso a glaucos, glandular pubescentes a glabros en la base, con dos líneas longitudinales de tricomas más cortos que los del resto del tallo; hojas ascendentes a levemente extendidas, disminuyendo de tamaño hacia el ápice de los tallos, sésiles a subsésiles, pecíolos $\leq 5 \mathrm{~mm}$ de largo; láminas foliares oblongo elípticas a lanceoladas, 2-7(9) $\times 0.5-2.5(3) \mathrm{cm}$, base cuneada a atenuada, en ocasiones redondeada, margen ondulado, en ocasiones rojizo, ápice agudo a obtuso, vilosas a esparcidamente glandular puberulentas o totalmente glabras, haz verde a glauca, envés glandular punteado, comúnmente más claro que el haz; sinflorescencias cimosas, ramas densamente glandular pubescentes, interrumpidas por hojas reducidas, bracteiformes; inflorescencias terminales o axilares, glomérulos 3 flores por involucro, pedúnculos 1-5 $\mathrm{mm}$ de largo, glandular pubescentes; involucro en la antesis campanulado, color verde a verde amarillento, 3-5(6) $\mathrm{mm}$ de largo, densamente glandular pubescente, lóbulos 2-3(3.5) × 1-2 mm, en fruto color marrón, translúcido, 6-8 $\mathrm{mm}$ de largo, lóbulos 3.5-5 × 2.5-3 mm; flores sésiles, perianto anchamente infundibuliforme, 4- $6 \mathrm{~mm}$ de largo, rosado a lila, lóbulos emarginados; estambres 3, exsertos; filamentos 5-7 mm de largo, del mismo color que el perianto, anteras globosas, 0.5-0.7 mm de diámetro, amarillas; estilo 
A
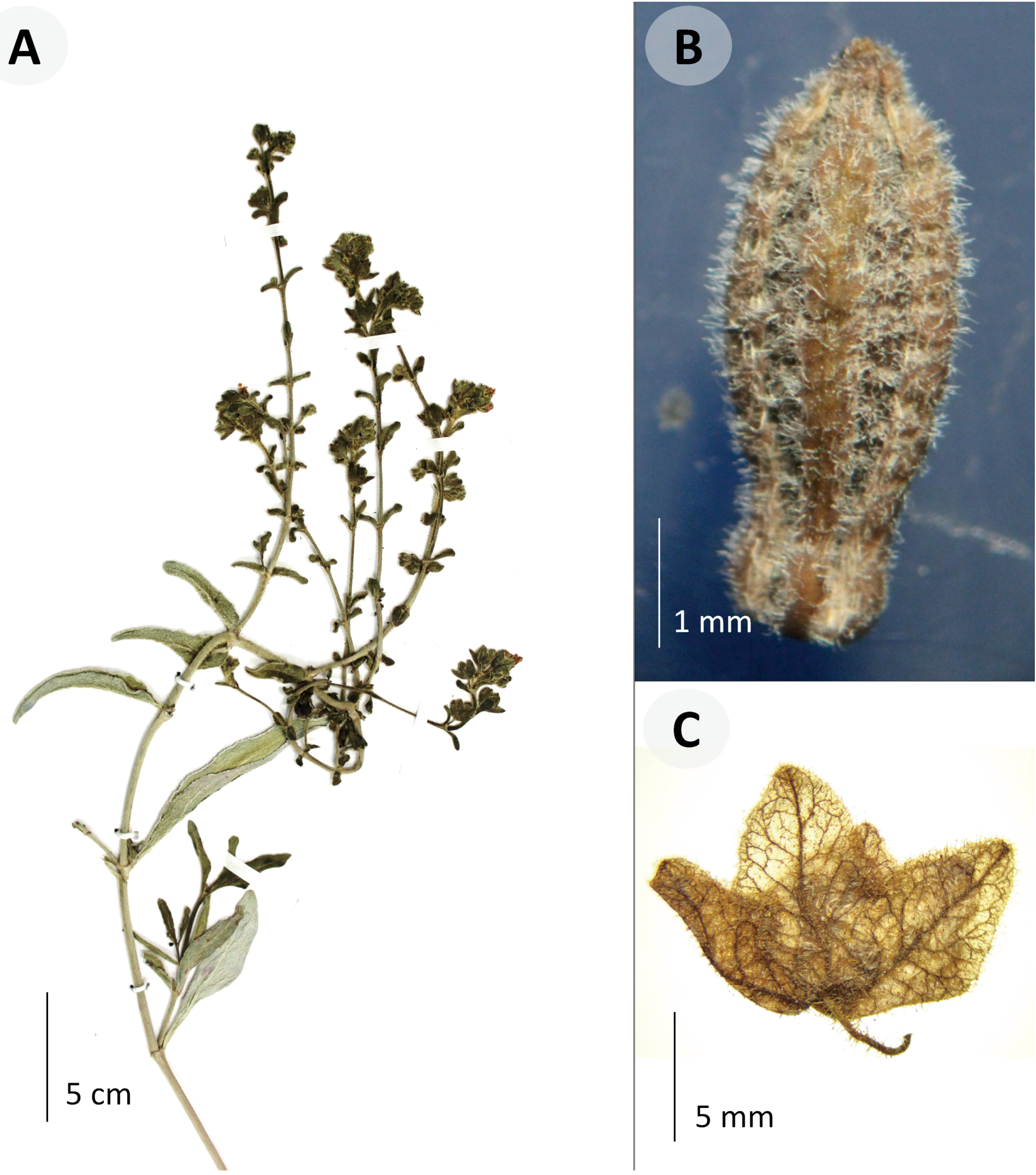

Figura 11: Mirabilis aggregata (Ortega) Cav. A. vista general; B. antocarpo; C. detalle de involucro maduro. 
filiforme, 7-9 mm de largo, exserto, del mismo color que el perianto, estigma capitado, con diminutas papilas estipitadas; antocarpo ovado, (3.5)4-5 mm de largo, constreñido en la base y el ápice, costillas prominentes, color marrón a marrón amarillento, cubierto por tricomas blanquecinos.

Distribución: endémica del centro de México (Spellenberg, 2001). Se ha registrado en Aguascalientes, Ciudad de México, Estado de México, Guanajuato, Hidalgo, Puebla y Zacatecas. En Aguascalientes es poco frecuente y se ha localizado en los municipios Aguascalientes, Asientos y Tepezalá (Fig. 12).

Hábitat: matorral xerófilo, en elevaciones de 17002200 m s.n.m.

Fenología: florece y fructifica de junio a noviembre.
Notas taxonómicas: Mirabilis aggregata es una especie polimórfica, cuya relacion con $M$. albida, que también es muy variante morfológicamente, aún debe esclarecerse; además, se ha sugerido puede hibridizar con otras del mismo género como M. glabrifolia (Spellenberg, 2001, 2003).

Ejemplares examinados: MÉXICO. Aguascalientes, municipio Aguascalientes, entre presa y la Hacienda San

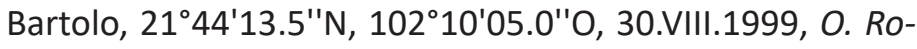
sales 1306 (HUAA); al O de Cieneguilla, lado E del Río San Pedro, 3.IX.2001, O. Rosales 1932 (HUAA). Municipio Asientos, $1.8 \mathrm{~km}$ al SE de Puerto de la Concepción, 22 11 '21.7"N, $102^{\circ} 07^{\prime} 21.3^{\prime \prime O}$, 21.VIII.2013, M. H. Sandoval 798 (HUAA).

Municipio Tepezalá, $500 \mathrm{~m}$ al E de Puerto de la Concepción, $22^{\circ} 12^{\prime} 10.1^{\prime \prime} \mathrm{N}, 102^{\circ} 07^{\prime} 52.4^{\prime \prime} \mathrm{O}, 26 . \mathrm{VI} .2013$, M. H. Sandoval 630 (HUAA).

- Mirabilis aggregata

- Mirabilis glabrifolia

- Mirabilis jalapa

- Mirabilis linearis

$\triangle$ Mirabilis longiflora

- Mirabilis viscosa

- Pisoniella arborescens

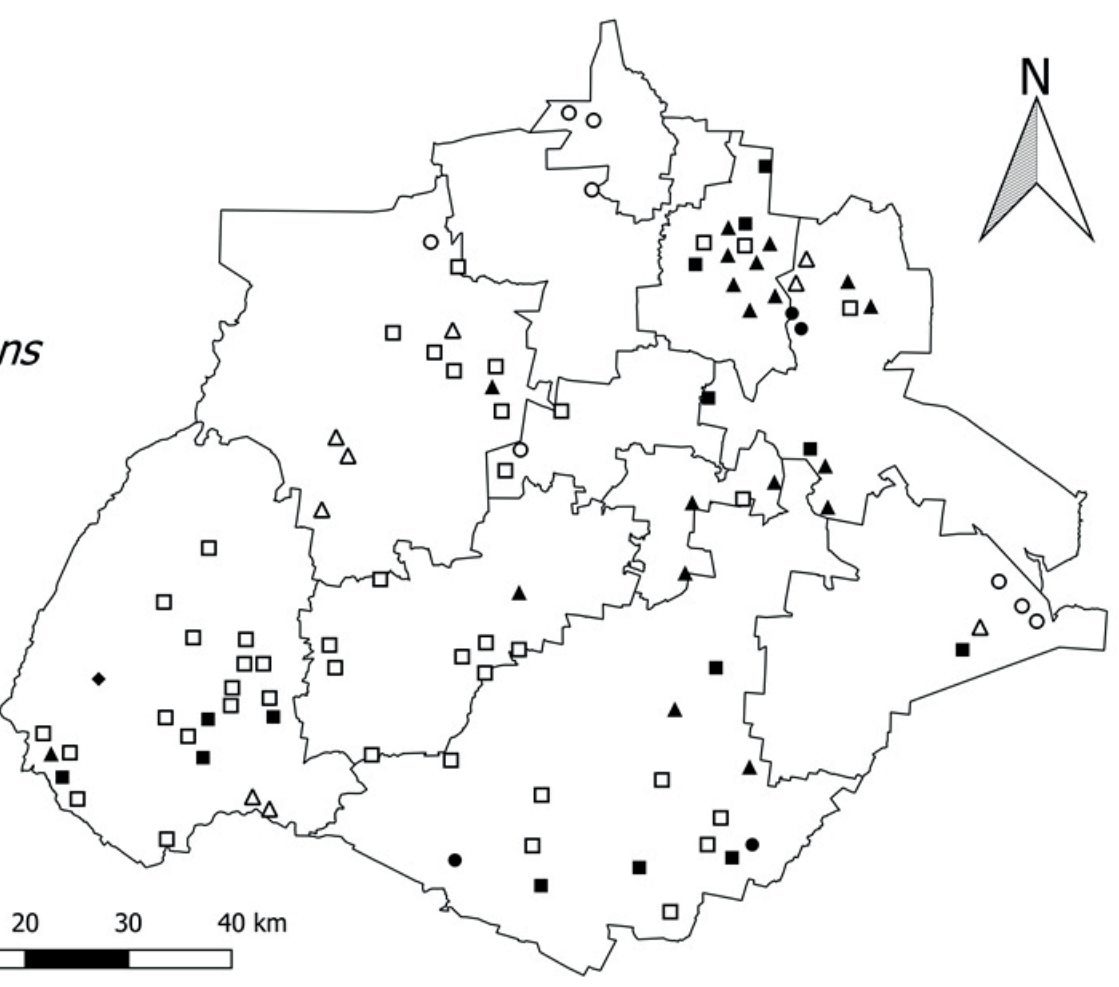

Figura 12: Distribución de las especies de los géneros Mirabilis L. y Pisioniella (Heimerl) Standl. en el estado de Aguascalientes, México. 
Mirabilis glabrifolia (Ortega) I.M. Johnst., J. Arnold Arbor. 25(2): 179. 1944. Fig. 13.

三 Mirabilis corymbosa Cav., Icon. 4(2): 55. t. 379. 1798. TIPO: MÉXICO. Lámina 379 de Icones et Descriptiones Plantarum 4(2): t. 379. 1798 (lectotipo: designado por Spellenberg, 2001).

三 Calymenia corymbosa (Cav.) Pers., Syn. PI. 1: 37. 1805.

三 Allionia corymbosa (Cav.) Kuntze, Revis. Gen. PI. 2: 533. 1891.

= Allionia microchlamydea Standl., Contr. U.S. Natl. Herb. 13(11): 405. 1911. TIPO: MÉXICO. Hidalgo, Ixmiquilpan, VII.1903, C. A. Purpus 429 (holotipo: US-00102929!).

= Allionia cardiophylla Standl., Contr. U.S. Natl. Herb. 13(11): 405. 1911. TIPO: MÉXICO. Oaxaca, 6 mi above (Santiago) Dominguillo, 30.X.1894, E. W. Nelson 1830 (holotipo: US-00102905!).

$\equiv$ Oxybaphus corymbosus (Cav.) Standl., Publ. Field Mus. Nat. Hist., Bot. Ser. 8(1): 10. 1930.

= Oxylobus microchlamideus (Standl.) Standl., Publ. Field Mus. Nat. Hist., Bot. Ser. 8(1): 10. 1930.

$=$ Mirabilis microchlamydea (Standl.) Standl., Publ. Field Mus. Nat. Hist., Bot. Ser. 8(5): 304. 1931.

Plantas perennes, herbáceas; tallos erectos a ascendentes, 20-60 cm de alto, nudos blanquecinos, rojizos o púrpuras, con una línea transversal de tricomas glandulares, entrenudos verde pálidos a glaucos, en ocasiones tornándose rojizos, glabros excepto por 1-2 líneas longitudinales de tricomas cortos glandulares y eglandulares; hojas pecioladas, las distales sésiles a subsésiles, pecíolos (0.5)1$5(5.5) \mathrm{cm}$ de largo, con una línea adaxial de tricomas similar a la de los tallos, láminas foliares deltoides a lanceoladas, (1)2-10(13) × (0.7)1.5-4 cm, disminuyendo de tamaño hacia el ápice, base trunca a levemente cuneada, rara vez subcordada, margen ondulado, entero o esparcidamente ciliado, comúnmente rojizo, ápice agudo a obtuso, glabras a esparcidamente puberulentas con tricomas eglandulares en ambas superficies; sinflorescencias cimosas, con ramas densamente glandular puberulentas; inflorescencias terminales o axilares, 1 flor por involucro, pedúnculos 1-2 mm de largo en la antesis, 2-5(7) $\mathrm{mm}$ de largo en fruto, glandular pubescentes; involucro en la antesis campanulado, herbáceo, 3-4 $\mathrm{mm}$ de largo, externamente glandular puberulento en toda su superficie o solo sobre las venas y el margen, lóbulos 2-2.5 × 1.3-2 mm, en fruto extendido, color marrón a veces con tonalidades púrpuras, translúscido, $6-7(8) \mathrm{mm}$ de radio, externamente glandular puberulento sobre las venas y en el margen, lóbulos prominentes, 3-4(6) × 2-4 mm, ápice agudo; perianto anchamente infundibuliforme, 4-6 $\mathrm{mm}$ de largo, rosado a lila, lóbulos emarginados; estambres 3, exsertos, filamentos 4-5 mm de largo, del mismo color que el perianto, anteras globosas, 0.5-0.6 mm de diámetro; estilo filiforme, 4.5-5 mm de largo, exserto, del mismo color que el perianto; estigma capitado, con diminutas papilas estipitadas; antocarpo ovado, 3.5-4 mm de largo, constreñido en la base y el ápice, costillas prominentes, color marrón a marrón amarillento, cubierto por tubérculos irregulares, blanquecinos, translúcidos y mucilaginosos al hidratarse.

Distribución: desde el sur de Estados Unidos de América hasta Chiapas (Spellenberg, 2001). En México se registra para Aguascalientes, Chiapas, Ciudad de México, Coahuila, Durango, Estado de México, Guanajuato, Hidalgo, Jalisco, Nuevo León, Oaxaca, Puebla, Querétaro, San Luis Potosí, Tamaulipas y Zacatecas. En Aguascalientes se distribuye en los municipios Aguascalientes, Asientos, Calvillo, Jesús María, San Francisco de los Romo, San José de Gracia y Tepezalá (Fig. 12).

Hábitat: matorral xerófilo, matorral subtropical y pastizal, en elevaciones de $1700-2200$ m s.n.m.

Fenología: florece y fructifica de junio a noviembre.

Ejemplares examinados: MÉXICO. Aguascalientes, municipio Aguascalientes, a $2.5 \mathrm{~km}$ al NO de Calvillito, $21^{\circ} 48^{\prime} 18.6^{\prime \prime} \mathrm{N}, 102^{\circ} 10^{\prime} 14.5^{\prime \prime O}, 28 . V I I I .2013$, M. H. Sandoval 811 (HUAA); $1.5 \mathrm{~km}$ al E de Aguascalientes (Ojo de Palmitas), 23.IX.1996, M. de la Cerda 5846 (HUAA). Municipio Asientos, $900 \mathrm{~m}$ al SE de Asientos, $22^{\circ} 13^{\prime} 51.1^{\prime \prime} \mathrm{N}$, $102^{\circ} 04^{\prime} 43.5^{\prime \prime} \mathrm{O}, 11 . \mathrm{XI} .2013$, M. E. Mendoza 1028 (HUAA); $3 \mathrm{~km}$ al $\mathrm{N}$ de El Llavero, $22^{\circ} 04^{\prime} 08.9^{\prime \prime} \mathrm{N}, 102^{\circ} 05^{\prime} 59.5^{\prime \prime} \mathrm{O}$, 6.IX.2012, M. H. Sandoval 102 (HUAA); bordo al extremo SO de Plutarco Elías Calles, $22^{\circ} 12^{\prime} 32.7^{\prime \prime} \mathrm{N}, 102^{\circ} 03^{\prime 25.7 " O,}$ 13.X.2012, M. H. Sandoval 248a (HUAA); $1.7 \mathrm{~km}$ al SE de EI 


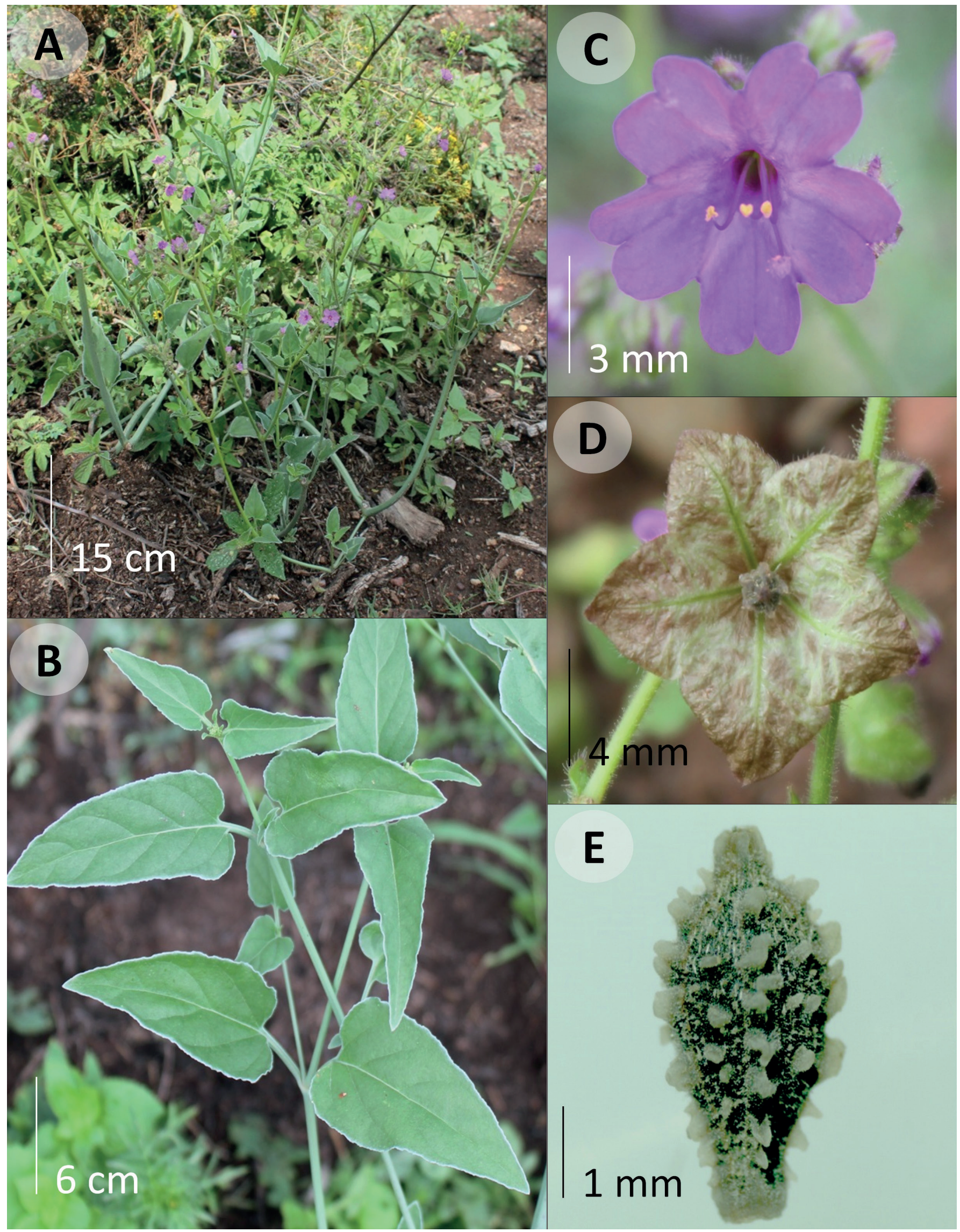

Figura 13: Mirabilis glabrifolia (Ortega) I.M. Johnst. A. vista general; B. detalle de hojas; C. flor; D. involucro maduro con antocarpo; E. antocarpo. 
Tule, 2201'58.9"N, 10205'51.0"O, 21.VIII.2013, M. H. Sandoval 791 (HUAA). Municipio Calvillo, $8 \mathrm{~km}$ al NO de Tapias Viejas, $21^{\circ} 51^{\prime} 52.0^{\prime \prime} \mathrm{N}, 102^{\circ} 37^{\prime} 16.2^{\prime \prime} \mathrm{O}$, 8.IX.2012, M. H. Sandoval 125a (HUAA); $500 \mathrm{~m}$ al SO de la cortina de la presa

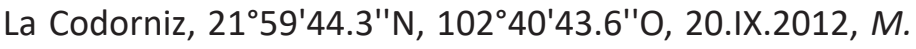
H. Sandoval 170a (HUAA); barranca Presa de los Serna, 1.8

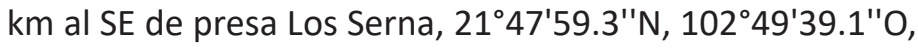
19.VII.2013, M. H. Sandoval 697 (HUAA). Municipio Jesús María, cortina de la presa El Jarabe a $4.5 \mathrm{~km}$ al SE de Jesús

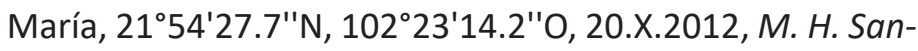
doval 275a (HUAA). Municipio San Francisco de los Romo, $1.8 \mathrm{~km}$ al SE de la colonia Macario J. Gómez, $21^{\circ} 58^{\prime} 30.3^{\prime \prime} \mathrm{N}$, $102^{\circ} 13^{\prime} 53.0^{\prime \prime O}$, 30.VIII.2014, M. E. Mendoza 828 (HUAA); $2.5 \mathrm{~km}$ al NO de Amapolas del Río, $22^{\circ} 03^{\prime} 17.5^{\prime \prime} \mathrm{N}$, $102^{\circ} 08^{\prime} 51.8^{\prime \prime O}$, 30.X.2013, M. E. Mendoza 847 (HUAA); $2 \mathrm{~km}$ al O de Borrotes, $22^{\circ} 02^{\prime} 12.3^{\prime \prime} \mathrm{N}, 102^{\circ} 13^{\prime} 29.4^{\prime \prime O}$, 4.VII.2013, M. H. Sandoval 678 (HUAA). Municipio San José de Gracia, $700 \mathrm{~m}$ al E de la cortina de la presa Plutarco Elías Calles, $22^{\circ} 08^{\prime} 17.0^{\prime \prime} \mathrm{N}, 102^{\circ} 24^{\prime} 47.0^{\prime \prime O}, 13 . X I I .2012$, M. H. Sandoval 511 (HUAA). Municipio Tepezalá, $1.4 \mathrm{~km}$ al NO de Tepeza-

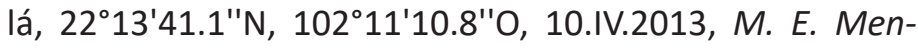
doza 495 (HUAA); $2.7 \mathrm{~km}$ al SE de Tepezalá, 22 $15^{\prime} 50.5^{\prime \prime} \mathrm{N}$, $102^{\circ} 09^{\prime} 07.8^{\prime \prime O}$, 2.VIII.2013, M. E. Mendoza 498 (HUAA); a Las Pilas, $22^{\circ} 15^{\prime} 32.7^{\prime \prime} \mathrm{N}, 102^{\circ} 10^{\prime} 18.3^{\prime \prime} \mathrm{O}, 8 . X I .2012, \mathrm{M}$. H. Sandoval 336 (HUAA); carretera Tepezalá - Puerto de la Concepción, a $3 \mathrm{~km}$ al SE de Tepezalá, $22^{\circ} 12^{\prime} 30.0^{\prime \prime} \mathrm{N}$, $102^{\circ} 08^{\prime 24.2 " O, ~ 26 . V I .2013, ~ M . ~ H . ~ S a n d o v a l ~} 626$ (HUAA); arroyo Las Pilas, $1.3 \mathrm{~km}$ al NO de Ex Hacienda Las Pilas, $22^{\circ} 15^{\prime} 43.5^{\prime \prime} \mathrm{N}, 102^{\circ} 10^{\prime} 32.4^{\prime \prime O}$, 2.VIII.2013, M. H. Sandoval 720 (HUAA); $1.2 \mathrm{~km}$ al SO de Tepezalá, $22^{\circ} 13^{\prime} 07.7^{\prime \prime} \mathrm{N}$, $102^{\circ} 10^{\prime} 47.5^{\prime \prime}$, 6.VI.2014, M. H. Sandoval 958 (HUAA).

Mirabilis jalapa L., Sp. PI. 1: 177. 1753. Fig. 14.

इ Nyctago jalapa (L.) DC., Fl. Franq. (3a ed.) 3: 426. 1805. TIPO: Sin localidad, s.f., G. Clifford 53 (lectotipo: BM000557976!, designado por Le Duc, 1993).

Plantas perennes, herbáceas; tallos ascendentes a erectos, 30-150 cm de alto, color verde, glabros o con 1-2 líneas longitudinales de tricomas eglandulares y septados; hojas pecioladas, pecíolos 1-3(4) cm de largo, glabros a esparcidamente puberulentos; láminas foliares ovadas a lan- ceoladas, 4-13(15) × 3-5(6) cm; base cuneada a redondeada, en ocasiones subcordada, margen entero, en ocasiones diminutamente ciliado, ápice agudo a acuminado, glabras a rara vez esparcidamente puberulentas; sinflorescencias en forma de cimas cortas; inflorescencias terminales o axilares, 1 sola flor por involucro, pedúnculos 5-12 mm de largo, glabros a esparcidamente puberulentos; invólucro campanulado, herbáceo, (6)8-16 mm de largo, glabro a esparcidamente puberulento, lóbulos lanceolados, (3)6-10 × 1.5-3(5) $\mathrm{mm}$, ápice acuminado, margen comúnmente ciliado, ligeramente acrescente en fruto; perianto infundibuliforme, 3545(50) mm de largo, lila o blanco, débilmente 5 lobulado, glabro; estambres 5 , exsertos, filamentos largos y delgados, 4-4.5 cm de largo, del mismo color que el perianto o levemente mas oscuros; estilo filiforme, $4.2-4.6 \mathrm{~cm}$ de largo, exserto, del mismo color que los filamentos, estigma capitado, diminutamente papilado; antocarpo ovado, 6-8 $\mathrm{mm}$ de largo, constreñido en la base y el ápice, costillas poco prominentes, rugoso, color marrón oscuro a marrón grisáceo, puberulento con tricomas blanquecinos adpresos.

Distribución: de Norte a Sudamérica, introducida en el viejo mundo (Spellenberg, 2001; 2003). En México se ha reportado para Aguascalientes, Baja California, Baja California Sur, Campeche, Chiapas, Ciudad de México, Chihuahua, Coahuila, Colima, Durango, Estado de México, Guanajuato, Hidalgo, Jalisco, Michoacán, Morelos, Nayarit, Nuevo León, Oaxaca, Puebla, Querétaro, Quintana Roo, Sinaloa, Sonora, Tabasco, Tlaxcala, Veracruz y Yucatán. En Aguascalientes se registra para los municipios Aguascalientes, Asientos, Calvillo, El Llano, Pabellón de Arteaga y Tepezalá (Fig. 12).

Hábitat: matorral xerófilo y vegetación secundaria, en elevaciones de 1700-2000 m s.n.m.

Fenología: florece y fructifica durante todo el año, principalmente de marzo a octubre.

Ejemplares examinados: MÉXICO. Aguascalientes, municipio Aguascalientes, $1 \mathrm{~km}$ al $\mathrm{S}$ del ejido Peñuelas, 31.VIII.1998, O. Rosales y M. Croce 137 (HUAA); $9 \mathrm{~km}$ al SSE del cruce carretera 45 a San Bartolo, $21^{\circ} 43^{\prime} 50.2^{\prime \prime} \mathrm{N}$, $102^{\circ} 11$ '06.9"O, 15.IX.2012, M. H. Sandoval 164 (HUAA); 


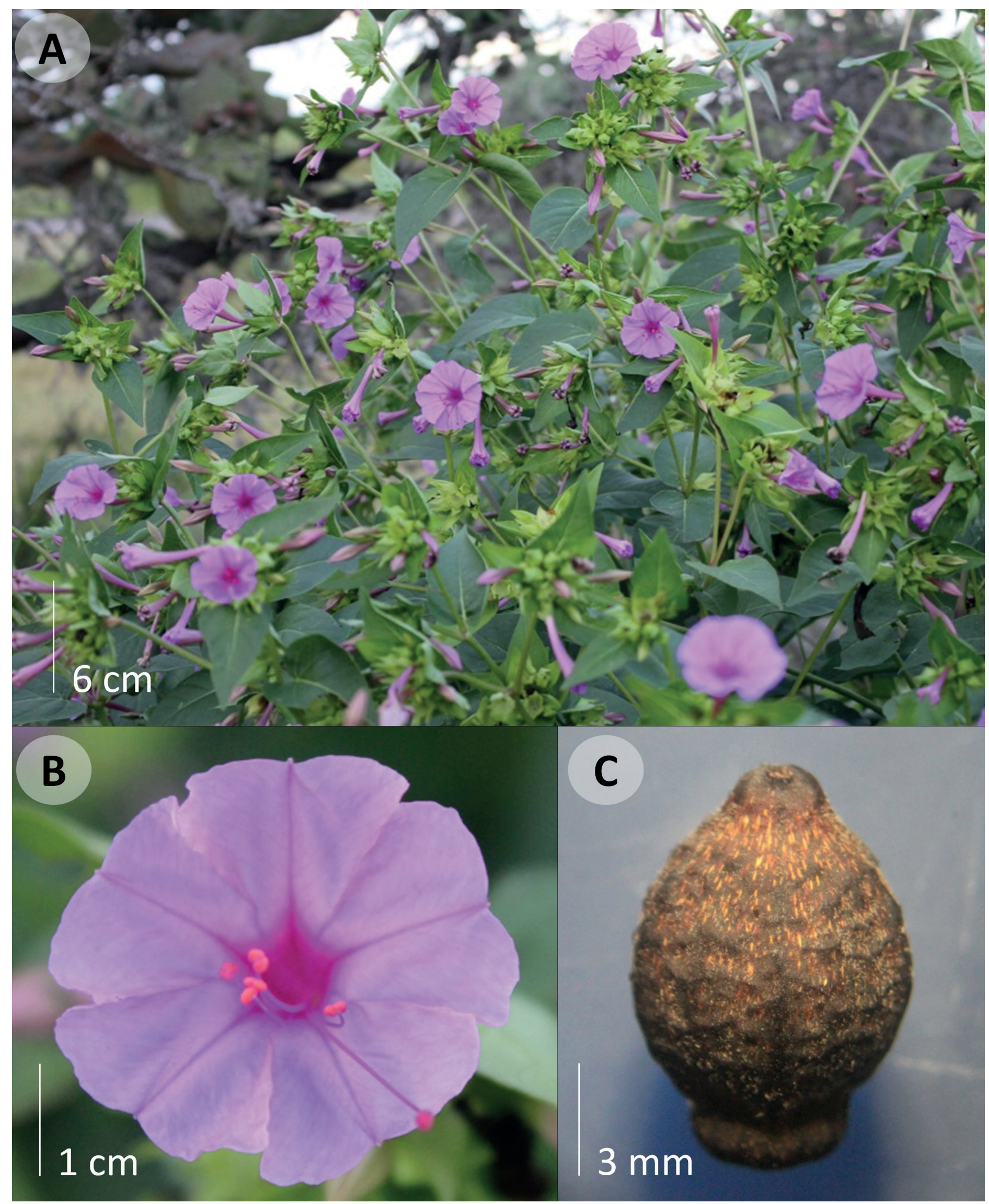

Figura 14: Mirabilis jalapa L. A. vista general; B. flor; C. antocarpo. 
Salto de Ojocaliente, $21^{\circ} 53^{\prime} 31.60^{\prime \prime} \mathrm{N}, 102^{\circ} 12^{\prime} 08.43^{\prime \prime O}$, 27.IX.1999, M. Croce s.n. (HUAA); $1 \mathrm{~km}$ al SE de Tanque de los Jiménez, $21^{\circ} 42^{\prime} 03.1^{\prime \prime} \mathrm{N}, 102^{\circ} 21^{\prime} 57.7^{\prime \prime} \mathrm{O}, 16 . \mathrm{VIII} .2013$, M. H. Sandoval 779 (HUAA). Municipio Asientos, $3 \mathrm{~km}$ al $\mathrm{N}$ de El Llavero, $22^{\circ} 04^{\prime} 08.8^{\prime \prime} \mathrm{N}, 102^{\circ} 05^{\prime} 59.5^{\prime \prime} \mathrm{O}, 6 . \mathrm{IX} .2012$, M. H. Sandoval 106 (HUAA); Mesa Mesillas, 22¹9'54"N, 10209'23"O, 21.VIII.2008, G. García 5486 (HUAA). Municipio Calvillo, $2.7 \mathrm{~km}$ al S de la presa Los Serna, barranca Tres Cruces, 6.IX.2001, G. García 4750 (HUAA; MEXU); Los Adobes, 20.IX.2001, G. García 4816 (HUAA); 8 km al NO de Tapias Viejas, $21^{\circ} 51^{\prime} 52.0^{\prime \prime} \mathrm{N}, 102^{\circ} 37^{\prime} 16.2^{\prime \prime O}$, 8.IX.2012, M. H. Sandoval 124 (HUAA); $500 \mathrm{~m}$ al SO de El Temazcal, $21^{\circ} 50^{\prime} 44.3^{\prime \prime} \mathrm{N}, 102^{\circ} 40^{\prime} 43.6^{\prime \prime} \mathrm{O}, 20 . I X .2012$, M. H. Sandoval 165 (HUAA); $3 \mathrm{~km}$ al SO de El Sauz, 2153'39.7"N, 102³8'41.7"O, 4.X.2012, M. H. Sandoval 205 (HUAA). Municipio El Llano, $1 \mathrm{~km}$ al SO de Palo Alto, $21^{\circ} 54^{\prime} 28.8^{\prime \prime} \mathrm{N}$, 10158'15.2"O, 24.VI.2013, M. H. Sandoval 615 (HUAA). Municipio Pabellón de Arteaga, $1.5 \mathrm{~km}$ al O del Cerro del Chiquihuite, 21.IX.1998, O. Rosales y M. Croce 183 (HUAA). Municipio Tepezalá, El Carmen, 4.5 km al O de Tepezalá, 14.X.1996, M. de la Cerda 5981 (HUAA); arroyo Las Pilas, $2 \mathrm{~km}$ al NO de la Ex Hacienda Las Pilas, 22 $15^{\prime} 59.1^{\prime \prime} \mathrm{N}$, 102 10'50.0"O, 2.VIII.2013, M. H. Sandoval 731 (HUAA).

Mirabilis linearis (Pursh) Heimerl, Annuaire Conserv. Jard.

Bot. Genève 5: 186. 1901. Fig. 15.

三 Allionia linearis Pursh, FI. Am. Sept. p. 728. 1814. TIPO: ESTADOS UNIDOS DE AMÉRICA. Louisiana, in upper Lousina, 21.VI.1810, J. Bradbury s.n. (holotipo: PH-00008129!). = Allionia diffusa Heller, Minn. Bot. Stud. 2: 33. 1898. TIPO: ESTADOS UNIDOS DE AMÉRICA. Nuevo México, on hills ten miles west of Santa Fe, 21.VI.1897, A. A. Heller 3740 (holotipo: MO-216364!).

三 Oxybaphus linearis (Pursh) B.L. Rob., Rhodora 10: 31. 1908.

Plantas perennes, herbáceas; tallos ascendentes a erectos, $15-70 \mathrm{~cm}$ de alto, color verde, densamente vilosos con tricomas simples o glandulares, con dos líneas longitudinales opuestas de tricomas más cortos que en el resto del tallo; hojas sésiles, rara vez pecioladas, pecíolos $\leq 3 \mathrm{~mm}$ de largo, láminas foliares lineares, 2-11 × 0.2-0.6 cm, las distales de menor tamaño, base atenuada, margen ciliado o entero, ápice agudo a obtuso, escasamente pubescentes a glabras en ambas superficies; sinflorescencias en forma de cimas de ramas cortas, con hojas subyacentes reducidas similares a las del tallo; inflorescencias terminales o axilares, glomérulos de 3 flores por involucro, pedúnculos 1-5 mm de largo, densamente víscido vilosos; involucro en la antesis campanulado, totalmente verde o con los márgenes y venas púrpura a rojizas, 4-5(6) $\mathrm{mm}$ de largo, densamente víscido viloso, lóbulos 3-4 × 1.5-2 mm, en fruto ampliamente campanulado a rotáceo, color verde amarillento a marrón, 6-8(10) mm de longitud, lóbulos 4-5 × 2-3 mm; perianto anchamente infundibuliforme, 10-12(15) $\mathrm{mm}$ de largo, lila a púrpura, lóbulos 5, emarginados; estambres 3, exsertos, filamentos 10-13 mm de largo, del mismo color que el perianto, anteras globosas, 0.5-0.7 mm de diámetro; estilo filiforme, 1.4-1.5 mm, exserto, del mismo color que el perianto, estigma capitado, con diminutas papilas estipitadas; antocarpo ovado, 4-5(6) $\mathrm{mm} \times 1.5-2(2.5) \mathrm{mm}$, constreñido en la base y en el ápice, costillas prominentes, color marrón a marrón amarillento, cubierto por tricomas blanquecinos.

Distribución: del centro-norte de los Estados Unidos de América hasta el centro de México (Spellenberg, 2001; 2003). En México se reporta para Aguascalientes, Chihuahua, Coahuila, Durango, Guanajuato, Querétaro y San Luis Potosí. En Aguascalientes se distribuye en los municipios Cosío, El Llano, Rincón de Romos, San Francisco de los Romo y San José de Gracia (Fig. 12).

Hábitat: bosque de Quercus y matorral xerófilo, en elevaciones de 2000-2200 m s.n.m.

Fenología: florece y fructifica de junio a noviembre.

Ejemplares examinados: MÉXICO. Aguascalientes, municipio Cosío, $1.2 \mathrm{~km}$ al SO de El Salero, 22²2'47.5"N, $102^{\circ} 20^{\prime} 03.5^{\prime \prime O}, 14 . V I I I .2013$, F. Cabrera 597 (HUAA). Municipio El Llano, rancho Los Robles, $1.5 \mathrm{~km}$ al NE de Ojo de Agua de Crucitas, $21^{\circ} 58^{\prime} 04.1^{\prime \prime} \mathrm{N}, 101^{\circ} 56^{\prime} 12.1^{\prime \prime O}$, 3.VII.2013, M. 


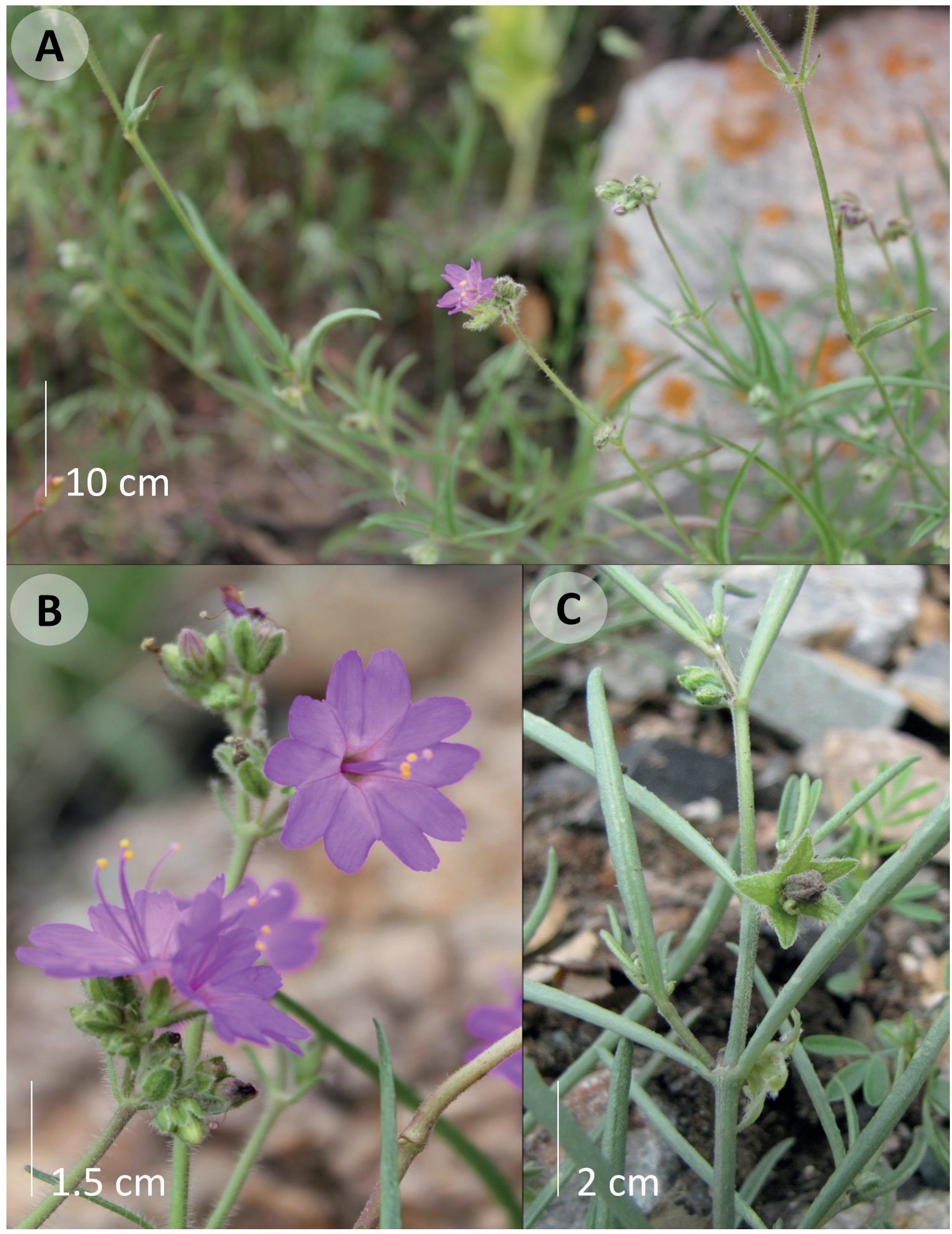

Figura 15: Mirabilis linearis (Pursh) Heimerl. A. vista general; B. flores; C. detalle de hojas y tallo con involucro maduro y antocarpo. 
H. Sandoval 672 (HUAA); barranca La Palma, $5.35 \mathrm{~km}$ al NE de Palo Alto, $21^{\circ} 56^{\prime} 46.7^{\prime \prime} \mathrm{N}, 101^{\circ} 54^{\prime} 54.0^{\prime \prime} \mathrm{O}, 17 . \mathrm{VII} .2013$, M. H. Sandoval 691 (HUAA); barranca de La Mina, a $6.7 \mathrm{~km}$ al NE de Palo Alto, $21^{\circ} 56^{\prime} 34.1^{\prime \prime} \mathrm{N}, 101^{\circ} 54^{\prime} 23.4^{\prime \prime O}, 17 . V I I .2013$, M. H. Sandoval 695 (HUAA). Municipio Rincón de Ro-

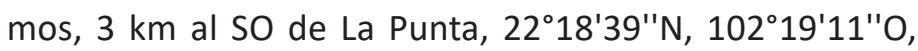
7.VIII.2013, J. C. Sierra 849 (HUAA). Municipio San Francisco de los Romos, a $4.7 \mathrm{~km}$ al O de Hacienda El Garabato, $22^{\circ} 04^{\prime} 57.8^{\prime \prime} \mathrm{N}, 102^{\circ} 23^{\prime} 10.8^{\prime \prime}$ O, 4.IX.2013, M. H. Sandoval 827 (HUAA). Municipio San José de Gracia, $3.5 \mathrm{~km}$ al NO de Las Camas, $22^{\circ} 15^{\prime} 52.7^{\prime \prime} \mathrm{N}, 102^{\circ} 28^{\prime} 16.6^{\prime \prime} \mathrm{O}, 27 . I X .2012$, M. H. Sandoval 190 (HUAA); extremo NE de San Antonio de los Ríos, $22^{\circ} 10^{\prime} 04.7^{\prime \prime} \mathrm{N}, 102^{\circ} 28^{\prime} 03.0^{\prime \prime O}$, 14.VI.2013, M. H. Sandoval 606 (HUAA).

Mirabilis longiflora L., Kongl. Svenska Vetensk. Acad. Handl. 16: 171-179, 1755. TIPO: No designado. Fig. 16.

= Mirabilis wrightiana A. Gray ex Britt. \& Kearney, Trans. New York Acad. Sci. 14: 28. 1895. TIPO: ESTADOS UNIDOS DE AMÉRICA. Nuevo México, Valley of Coppermine Creek, near Santa Rita, 4.VIII.1951, C. Wright 1702 (holotipo: GH00001017!, isotipo: GH-00001018!).

= Mirabilis longiflora var. wrightiana (A. Gray ex Britton \& Kearney) Kearney \& Peebles, J. Wash. Acad. Sci. 29(11): 475. 1939.

Plantas perennes, herbáceas; tallos ascendentes a erectos, 0.6-1.5 m de alto, glandular pubescentes; hojas pecioladas, las distales sésiles o subsésiles, pecíolos 1-4 cm de largo; láminas foliares cordadas, 4-10 × 3-6 cm, base cordada, margen entero, diminutamente ciliado, ápice agudo a acuminado, glandular-pubescentes en toda su superficie o solo sobre las venas; sinflorescencias en forma de cimas cortas; inflorescencias terminales o axilares, 1 sola flor por involucro, pedúnculos 3-5(6) mm de largo, glandular pubescentes; invólucro campanulado, herbáceo, ligeramente acrescente en fruto, (5)7-14(15) mm de largo, lóbulos (3)4-8(10) × 1.5-3(5) mm, margen entero o ciliado, ápice acuminado; perianto infundibuliforme, 60-100(150) $\mathrm{mm}$ de largo, blanco o rosa pálido, lóbulos de ápice emarginado, comúnmente alternándose con franjas de color rosado intenso que en conjunto forman una estrella en el centro; estambres 5, exsertos, filamentos (9)10-13 cm de largo, color lila o rosados; estilo filiforme, 8-12 cm de largo, exserto, del mismo color que los filamentos, estigma capitado, diminutamente papilado; antocarpo ovado, 8-9 mm de largo, constreñido en la base y el ápice, rugoso, costillas poco prominentes, color marrón oscuro a marrón grisáceo, puberulento con tricomas blanquecinos adpresos.

Distribución: desde el suroeste de los Estados Unidos de América hasta el sur de México (Spellenberg, 2001; 2003). En México se reporta en Aguascalientes, Chihuahua, Ciudad de México, Coahuila, Durango, Estado de México, Guanajuato, Hidalgo, Michoacán, Morelos, Nuevo León, Oaxaca, Puebla, Querétaro, San Luis Potosí, Sinaloa, Tlaxcala y Veracruz. En Aguascalientes se distribuye en los municipios Calvillo, San José de Gracia y Tepezalá (Fig. 12).

Hábitat: bosque de Quercus, matorral subtropical y matorral xerófilo, en elevaciones de 1900-2300 m s.n.m.

Fenología: florece y fructifica de junio a noviembre.

Ejemplares examinados: MÉXICO. Aguascalientes, municipio Calvillo, $2 \mathrm{~km}$ al NE de Palo Alto, 31.VIII.1985, G. García 2521 (HUAA, IEB); Barranca Oscura, 23.I.2007, O. Rosales 3890 (HUAA); $0.6 \mathrm{~km}$ al SE de rancho Las Joyas, $21^{\circ} 46^{\prime} 40.1^{\prime \prime} \mathrm{N}, 102^{\circ} 38^{\prime} 12.0^{\prime \prime O}$, 11.X.2013, M. H. Sandoval 887 (HUAA). Municipio San José de Gracia, 700 m al O de la Estación Biológica Agua Zarca, 2205'13.1"N, $102^{\circ} 33^{\prime} 13.8^{\prime \prime O}$, 6.X.2012, M. H. Sandoval 214 (HUAA); 600 $\mathrm{m}$ al NO de la Estación Biológica Agua Zarca, 2205'35.9" $\mathrm{N}$, $102^{\circ} 33^{\prime} 34.9^{\prime \prime O}$, 6.X.2012, M. H. Sandoval 234 (HUAA); Presa 50 Aniversario, 21.IX.1989, G. García-Regalado 2857 (HUAA; IEB); Hacienda Santa Rosa, 2201'47.1"N, 102³4'22.2"O, 19.VIII.2013, M. H. Sandoval 781 (HUAA). Municipio Tepezalá, La Minerva, 23.VII.1982, M. de la Cerda y G. García 1421 (HUAA); cerro San Juan, 21.VIII.2000, G. González 434 (HUAA).

Mirabilis viscosa Cav., Icon. 1: 13, t. 19. 1791. TIPO: MÉXICO. Lámina 19, de Icones et Descriptiones Plantarum Cav., Icon. 1: 13, t. 19. 1791 (lectotipo: designado por Spellenberg, 2001). Fig. 17. 


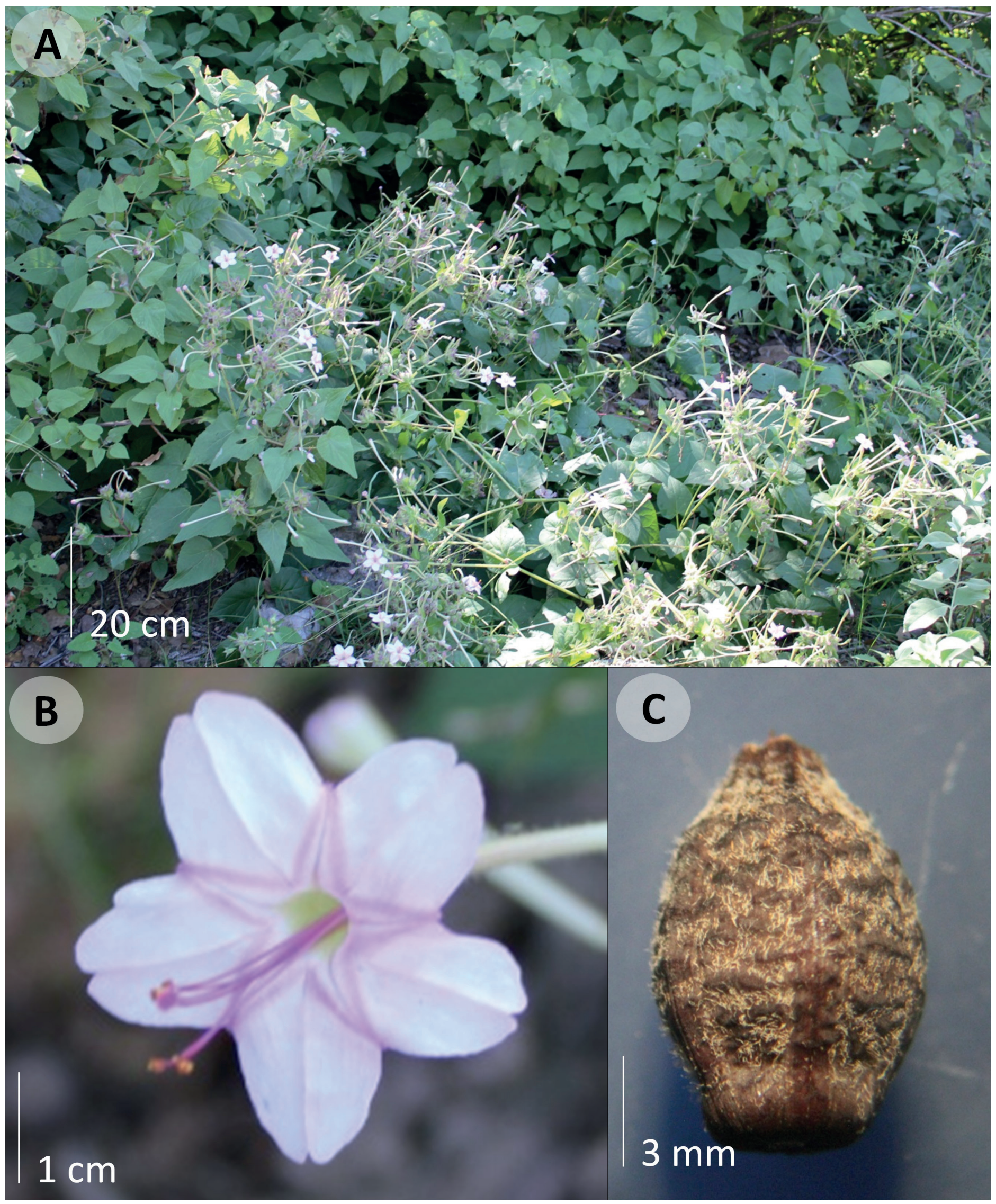

Figura 16: Mirabilis longiflora L. A. vista general; B. flor; C. antocarpo. 
三 Oxybaphus viscosus (Cav.) L'Hér. ex Choisy, in DC. Prodr. 13: 430. 1849.

इAllionia viscosa (Cav.) Kuntze, Rev. Gen. PI. 2: 533. 1891.

Plantas perennes, herbáceas; tallos erectos a ascendentes, $20-80 \mathrm{~cm}$ de alto, glandular pubescentes; pecíolos (0.5)1-5(5.5) cm de largo, glandular pubescentes; láminas foliares cordadas, (1)2-10(12) × (0.7)1.5-6(8) cm de ancho, disminuyendo de tamaño hacia el ápice de los tallos, base cordada, margen ciliado, ápice agudo a obtuso, densa a esparcidamente glandular pubescentes en ambas superficies; sinflorescencias en forma de cimas cortas, ramas densamente glandular pubescentes; inflorescencias terminales o axilares, 1 flor por involucro, pedúnculos glandular pubescentes, 1-2 mm en la antesis, 2-6 mm en fruto; invólucro en la antesis campanulado, herbáceo, 2-3 mm de largo, lóbulos 1-2 × 0.5$0.8(1) \mathrm{mm}$, en fruto extendido y rotáceo, papiráceo, color marrón o marrón amarillento, translúcido, (6)10-15 mm de radio, externamente glandular puberulento, los lóbulos ausentes a débilmente prominentes, ápice obtuso a redondeado; perianto anchamente infundibuliforme, (6)8-10(12) mm de radio, color rosado a lila, lóbulos emarginados; estambres 3, exsertos; filamentos 1-1.3(1.5) cm de largo, del mismo color que el perianto, anteras globosas, 0.8-1 mm de diámetro; estilo filiforme, 10-13 mm de largo, exserto, del mismo color que el perianto, estigma capitado, diminutamente papilado; antocarpo ovado, 4.5-5 mm de largo, constreñido en la base y el ápice, costillas prominentes, color marrón a marrón amarillento, cubierto con tubérculos prominentes, irregulares, translúcidos y mucilaginosos al hidratarse.

Distribución: del norte y centro de México hasta el noroeste de Sudamérica (Spellenberg, 2001). En México se ha registrado en Aguascalientes, Chihuahua, Durango, Guanajuato, Hidalgo, Jalisco, Michoacán, Morelos, Oaxaca, Puebla, Querétaro, Tamaulipas, Tlaxcala, Veracruz y Zacatecas. En Aguascalientes se reporta para los municipios Aguascalientes, Asientos, Calvillo, Jesús María, San Francisco de los Romo, San José de Gracia y Tepezalá (Fig. 12).

Hábitat: bosque de Quercus, bosque de galería, matorral subtropical, matorral xerófilo, pastizal y vegetación secundaria en elevaciones de $1700-2000$ m s.n.m.
Fenología: florece y fructifica de finales de febrero a noviembre.

Ejemplares examinados: MÉXICO. Aguascalientes, municipio Aguascalientes, faldas del Cerro del Picacho, $21^{\circ} 53^{\prime} 13.7^{\prime \prime} \mathrm{N}, 102^{\circ} 25^{\prime} 08.7^{\prime \prime O}$, 22.XI.2013, M. H. Sandoval 924 (HUAA); $9 \mathrm{~km}$ al SSE del cruce carretera 45 a San Bartolo, $21^{\circ} 43^{\prime} 50.2^{\prime \prime} \mathrm{N}, 102^{\circ} 11^{\prime} 06.9^{\prime \prime O}$, 15.IX.2012, M. H. Sandoval 161 (HUAA); $0.5 \mathrm{~km}$ al NE de la planta CFE carretera 69 a San Bartolo, $21^{\circ} 45^{\prime} 38.40^{\prime \prime} \mathrm{N}, 102^{\circ} 11^{\prime} 51.60^{\prime \prime} \mathrm{O}, 15 . \mathrm{IX} .2012$, M. H. Sandoval 138 (HUAA); salto de Los Salado - Sabinal, 23.X.1994, C. Carrillo 99 (HUAA). Municipio Asientos, bordo al extremo SW de Plutarco Elías Calles, 22²'32.7"N, 10203'25.7"O, 13.X.2012, M. H. Sandoval 248 (HUAA). Municipio Calvillo, $3 \mathrm{~km}$ al SO de El Sauz, $21^{\circ} 53^{\prime} 39.7^{\prime \prime} \mathrm{N}$, $102^{\circ} 38^{\prime} 41.7^{\prime \prime O}, 29 . I X .2012$, M. H. Sandoval 204 (HUAA); barranca Presa de los Serna, extremo SE de presa de los Ser-

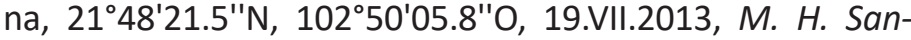
doval 698 (HUAA); $25 \mathrm{~km}$ al O de Aguascalientes, carretera Aguascalientes - Calvillo, 10.VIII.1996, M. de la Cerda 5662 (HUAA, IEB, MEXU); huerta El Chilarillo, arroyo Los Caballos, 2.X.1994, G. Nieto 62 (HUAA); márgenes de la presa La Ordeña Vieja, $21^{\circ} 56^{\prime} 53.3^{\prime \prime} \mathrm{N}, 102^{\circ} 43^{\prime} 14.8^{\prime \prime} \mathrm{O}, 28 . V I .2013$, M. H. Sandoval 640 (HUAA); 5 km de La Labor, carretera a Calvillo, 8.X.1982, M. E. Siqueiros 1950 (HUAA); arroyo de Malpaso, 12.XI.1982, M. E. Siqueiros 1987 (HUAA); libramiento a Jalpa, al E de Calvillo, 22.IX.2004, O. Rosales 3233 (HUAA); O del poblado de Calvillo, 29.X.1997, M. de la Cerda 5092 (HUAA). Municipio Jesús María, $1.3 \mathrm{~km}$ al NNO de La Tomatina, $22^{\circ} 54^{\prime} 49.2^{\prime \prime} \mathrm{N}, 102^{\circ} 25^{\prime} 05.7^{\prime \prime O}, 11 . X .2012$, M. H. Sandoval 238 (HUAA); $26.7 \mathrm{~km}$ por carretera a Calvillo, 13.VI.1984, M. Hernández 238 (MEXU); Hacienda La Bóveda, Cerro del Colorín, 30.IX.1983, M. E. Siqueiros 2477 (HUAA). Municipio San Francisco de los Romo, $5 \mathrm{~km}$ al NE de Cañada Honda, $22^{\circ} 02^{\prime} 24.0^{\prime \prime} \mathrm{N}, 102^{\circ} 10^{\prime} 37.8^{\prime \prime} \mathrm{O}, 30 . \mathrm{VIII} .2014$, M. E. Mendoza 833 (HUAA); a $4.7 \mathrm{~km}$ al O de Hacienda El Garabato, $22^{\circ} 04^{\prime} 57.8^{\prime \prime} \mathrm{N}, 102^{\circ} 23^{\prime} 10.8^{\prime \prime O}, 4 . I X .2013$, M. H. Sandoval 822 (HUAA). Municipio San José de Gracia, barranca El Carrizal a $4.5 \mathrm{~km}$ al NO de San Antonio de los Ríos, $22^{\circ} 11^{\prime} 05.8^{\prime \prime} \mathrm{N}$, $102^{\circ} 30^{\prime} 23.5^{\prime \prime O}$, 17.IV2013, M. H. Sandoval 556 (HUAA); boca del Túnel de Potrerillo, $22^{\circ} 14^{\prime} 34.7^{\prime \prime} \mathrm{N}, 102^{\circ} 26^{\prime} 43.9^{\prime \prime O}$, 12.VI.2013, M. H. Sandoval 586 (HUAA); barranca al extremo NE de San José de Gracia, 2209'20.6"N, 102²4'35.3"O, 


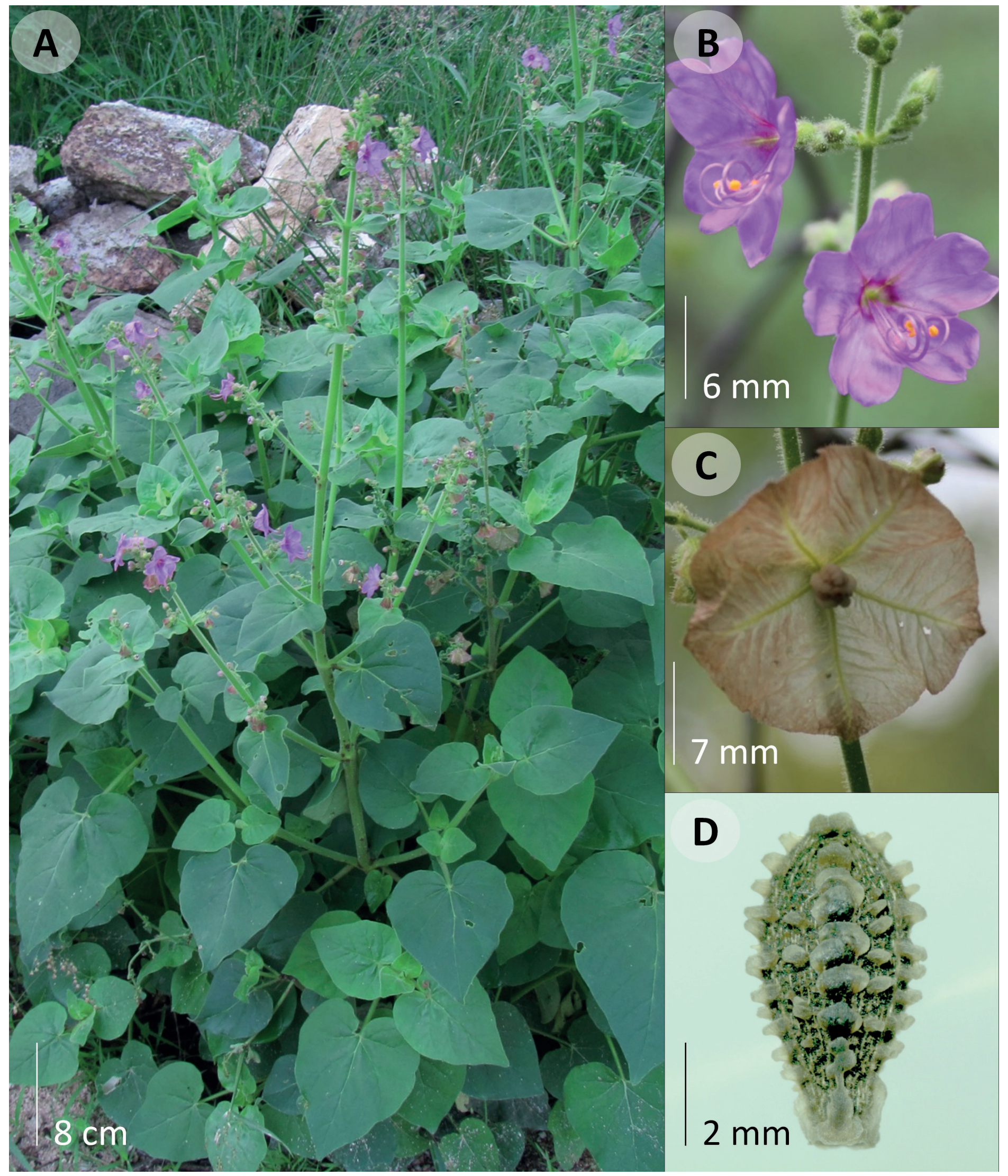

Figura 17: Mirabilis viscosa Cav. A. vista general; B. flores; C. involucro maduro con antocarpo; D. antocarpo. 
14.VI.2013, M. H. Sandoval 591 (HUAA); extremo NE de San Antonio de los Ríos, $22^{\circ} 10^{\prime} 04.7^{\prime \prime} \mathrm{N}, 102^{\circ} 28^{\prime} 03.0^{\prime \prime O}$, M. H. Sandoval 597 (HUAA); presa Calles (cañón), 4.III.1985, M. E. Siqueiros 2751 (HUAA). Municipio Tepezalá, arroyo Las Pilas, $1.3 \mathrm{~km}$ al NO de Ex Hacienda Las Pilas, 22 ${ }^{\circ} 15^{\prime} 43.5^{\prime \prime} \mathrm{N}, 102$ 10'32.4"O, 2.VIII.2013, M. H. Sandoval 723 (HUAA); arroyo Las Pilas, $2 \mathrm{~km}$ al NO de la Ex Hacienda Las Pilas, 22 $15^{\prime} 59.1^{\prime \prime} \mathrm{N}$, 102 10'50"O, 2.VIII.2013, M. H. Sandoval 728 (HUAA).

Pisoniella (Heimerl) Standl., Contr. U.S. Natl. Herb. 13(11): 385. 1911. TIPO: Pisoniella arborescens (Lag. \& Rodr.) Standl.

Plantas perennes, arbustivas; tallos ascendentes o erectos, ramificados en forma divaricada, aparentando ser dicotómicos, inermes; hojas comúnmente subiguales, pecioladas, enteras, delgadas, glabrescentes más o menos concoloras en ambas caras; inflorescencias umbelas congestas, terminales y axilares, pedunculadas, pedúnculos delgados; involucro de brácteas libres, pequeñas, persistentes, angostamente lanceoladas u oblanceoladas, en ocasiones pubérulas, no acrescentes; flores actinomorfas, bisexuales, cortamente pediceladas, casmógamas, vistosas, perianto membranáceo, tubular-campanulado, no constreñido basalmente por arriba del ovario; estambres 6-11, exsertos, unidos en la base en un anillo carnoso, ginóforo presente, ovario alargado, estilo exserto, estigma capitado; antocarpo clavado, simetría radial, levemente curvo, coriáceo, costillas comúnmente 5 , redondeadas, conspicuamente cubiertas de glándulas víscidas capitadas, irregularmente espaciadas.

Género con dos especies, una restringida a México, la otra en Sudamérica (Standley, 1911; Spellenberg, 2001).

Pisoniella arborescens (Lag. \& Rodr.) Standl., Contr. U.S. Natl. Herb. 13(11): 385. 1911. Fig. 18.

三 Boerhavia arborescens Lag. \& Rodr., Anales Ci. Nat. 4(12): 257. 1801. TIPO: MÉXICO. Guanajuato, Salvatierra, s.f., $M$. S. Lagasca y J. D. Rodríguez s.n. (holotipo: MA-235253!).

Plantas perenne, arbustivas; tallos ascendentes, delgados, cilíndricos, comúnmente sostenidos por vegetación vecina, 0.6-5 m de alto, corteza marrón grisácea o rojiza, cubierta por lenticelas, densamente puberulentos cuando jóvenes, glabrescentes; hojas subiguales, pecíolos 0.5-2(3) $\mathrm{cm}$ de largo, puberulentos; láminas foliares ovadas a orbiculares, 1-10 × 1-7 cm, base cuneada, redondeada u oblicua, margen ciliado, ápice agudo a redondeado, haz más oscuro que el envés, esparcidamente puberulentas en ambas superficies, principalmente sobre las venas; inflorescencias umbelas 20-25(30) flores, pedúnculos 2-5(9) cm de largo, puberulentos; flores subsésiles, pedicelos 1-2 mm de largo, puberulentos; perianto $4-5 \mathrm{~mm}$ de largo, proximalmente verdoso, puberulento, con 5 venas más oscuras que el resto de la superficie y varias glándulas víscidas de color rojizo, distalmente blanco, eglandular, viloso puberulento; estambres 6-11, exsertos, 1.5- 2 veces más largos que el tubo del perianto, filamentos (6)7-10 mm de largo; estilo igual o ligeramente más largo que los filamentos, estigma capitado; antocarpo clavado, 10-13 mm de largo, color verde a marrón, costillas 5 , con glándulas víscidas rojizas u oscuras, más numerosas cerca del ápice.

Distribución: especie endémica de México y restringida al centro del país (Standley, 1911; Spellenberg, 2001). Reportada para Ciudad de México, Estado de México, Guanajuato, Hidalgo, Jalisco, Michoacán, Oaxaca, Querétaro y Veracruz. Se reporta por primera vez para Aguascalientes, en el municipio Calvillo (Fig. 12).

Hábitat: bosque tropical caducifolio, en elevaciones de 1700 m s.n.m.

Fenología: florece de marzo a octubre y fructifica de junio a noviembre.

Ejemplares examindados: MÉXICO. Aguascalientes, municipio Calvillo, cascada Los Huenchos, $21^{\circ} 52^{\prime} 49.4^{\prime \prime} \mathrm{N}$, $102^{\circ} 46^{\prime} 53.9^{\prime \prime O}, 16 . X .2014$, J. C. Sierra 924 (HUAA).

\section{Discusión}

En Aguascalientes se distribuyen seis géneros y 15 especies de la familia Nyctaginaceae, riqueza comparable con estados de mayor superficie como Hidalgo, para el que se registran ocho géneros y 16 especies (Hernández-Ledesma 


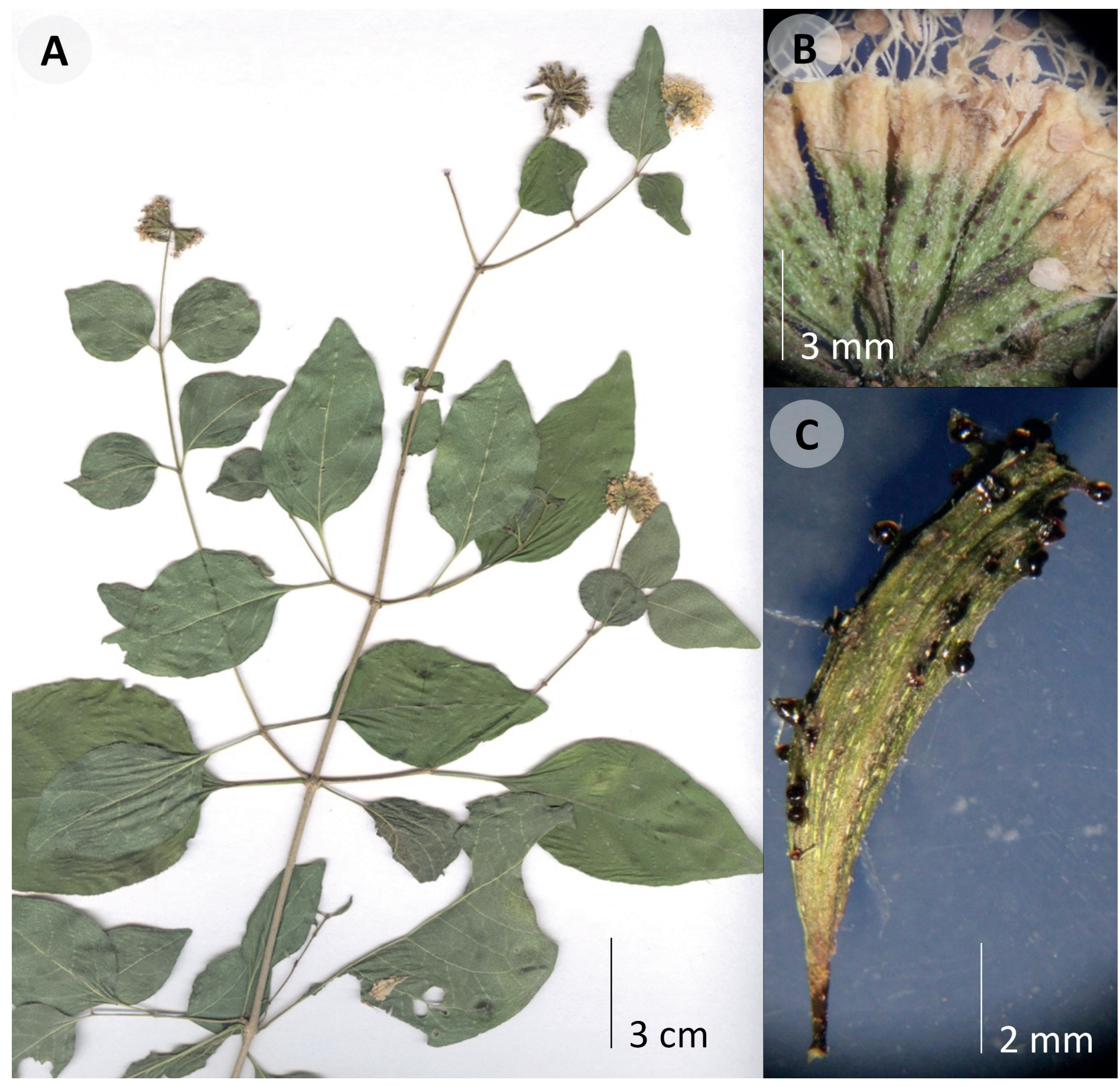

Figura18: Pisoniella arborescens (Lag. \& Rodr.) Standl. A. vista general; B. inflorescencia; C. antocarpo.

y Flores-Olvera, 2003) y Veracruz, para el que se reportan nueve géneros y 16 especies silvestres (Fay, 1980). Cabe mencionar que no se incluye el género Bougainvillea, que en México está representado solo por especies ornamentales introducidas que no han llegado a naturalizarse (Spellenberg, 2001).
En el territorio nacional, se han catalogado como malezas alrededor de 15 especies de esta familia, la mayoría pertenecientes al género Boerhavia (Villaseñor y Espinosa-García, 1998), entre las cuales se encuentran $B$. coccinea y B. erecta, ambas nativas (Villaseñor, 2016) pero actualmente distribuidas en regiones tropicales y subtropi- 
cales del mundo (Spellenberg, 2001; 2003). La primera es un elemento común en áreas con vegetación secundaria de la mayoría de los municipios del estado, mientras que $B$. erecta es escasa y se encuentra únicamente en el municipio Calvillo.

Otra especie poco común en el área de estudio es Pisoniella arborescens, que ha sido reportada de Jalisco a Oaxaca (Fay, 1980; Spellenberg, 2001; Hernández-Ledesma y Flores-Olvera, 2003) y se registra por primera vez en Aguascalientes. Pese a que es considerada una maleza (Villaseñor y Espinosa-García, 1998) y que algunos autores (Fay, 1980; Spellenberg, 2001; Hernández-Ledesma y Flores-Olvera, 2003) la mencionan como un elemento de vegetación secundaria o áreas con disturbio de matorral xerófilo, bosque tropical caducifolio y bosque de Quercus, dentro del estado se ha encontrado únicamente en un área conservada de bosque tropical caducifolio, en el municipio Calvillo.

El género de la familia Nyctaginaceae con mayor número de especies dentro del área de estudio es Mirabilis, con un total de seis, solo una menos que las reportadas para Hidalgo (Hernández-Ledesma y Flores-Olvera, 2003), dos más que en Veracruz (Fay, 1980) y una más que en Guerrero (Zavala-Téllez y Fonseca, 2014). Por otra parte, M. jalapa y $M$. viscosa son taxones con distribución amplia en el estado; se encuentran en áreas con disturbio de matorral xerófilo y matorral subtropical. Mirabilis viscosa crece en Aguascalientes, Calvillo, Jesús María, San Francisco de los Romo y San José de Gracia, mientras que M. jalapa en Aguascalientes, Calvillo, El Llano y Pabellón de Arteaga. De igual forma ambas se localizan en zonas con vegetación secundaria en Asientos y Tepezalá.

Mirabilis jalapa es también la única especie de la familia para la que hay un uso reportado en el estado; es utilizada como ornamental debido a sus flores coloridas (Barba-Ávila et al., 2003), por lo que es común encontrarla cerca de poblados. Algunas plantas domésticas presentan flores variegadas, de colores distintos a las silvestres, como amarillo con franjas rojas o blanco con franjas violeta, entre otros; en el área de estudio se le conoce con el nombre de "maravilla" y es también una maleza común en camellones y jardineras de áreas urbanas.

Aunque la familia Nyctaginaceae está bien representada en el centro y suroeste del estado, es en la zona noreste, en la que predomina la vegetación árida como matorral xerófilo o pastizales (Siqueiros-Delgado et al., 2017), donde se encuentra la mayor riqueza de especies, principalmente en los municipios Asientos y Tepezalá.

\section{Conclusiones}

Aguascalientes cuenta con dos tribus, seis géneros y 15 especies de Nyctaginaceae, principalmente distribuidas en Asientos y Tepezalá, en matorral xerófilo. Existen elementos de esta familia que son comunes en otras áreas del país, pero en el estado son poco frecuentes, por lo que se podrían realizar estudios que den a conocer las razones de su distribución limitada en esta región. El presente estudio contribuye al conocimiento de la flora del estado y de la familia Nyctaginaceae en México.

\section{Contribución de autores}

MHSO, MESD y RCT concibieron y diseñaron el estudio. MHSO realizó colectas, identificó ejemplares, elaboró el manuscrito y las figuras. MESD, RCT y GO revisaron el manuscrito. Todos los autores contribuyeron a la discusión y aprobación del manuscrito final.

\section{Financiamiento}

Este estudio fue apoyado por el Consejo Nacional de Ciencia y Tecnología a MHSO (número de beca 354518 ) y Comisión Nacional para el Conocimiento y Uso de la Biodiversidad a MESD (número de proyecto JF140).

\section{Agradecimientos}

A Julio Martínez Ramírez, técnico del Herbario de la Universidad Autónoma de Aguascalientes por todo el apoyo brindado durante el desarrollo de este trabajo. A Gerardo García Regalado, Florencia Cabrera Manuel y Hugo Noé Araiza Arvilla por su ayuda durante la colecta de ejemplares.

\section{Literatura citada}

Barba-Ávila, M. de los D., M. Croce-Hernández y M. de la CerdaLemus. 2003. Plantas útiles de la región semiárida de Aguascalientes. Universidad Autónoma de Aguascalientes. Aguascalientes, México. 235 pp.

Calderón de Rzedowski, G. 2005. Nyctaginaceae. In: Rzedowski, J. y G. Calderón de Rzedowski (eds.). Flora fanerogámica del 
Valle de México. (2a ed.). Instituto de Ecología, A.C. y Comisión Nacional para el Conocimiento y Uso de la Biodiversidad. México, D.F., México. Pp. 133-138.

CONABIO. 2008. La Biodiversidad en Aguascalientes: Estudio de Estado. Comisión Nacional para el Conocimiento y Uso de la Biodiversidad, Instituto del Medio Ambiente del Estado de Aguascalientes, Universidad Autónoma de Aguascalientes. México, D.F., México. 384 pp.

Curators Herbarium B. 2020. Digital specimen images at the Herbarium Berolinense. Botanic Garden and Botanical Museum Berlin. Berlin, Germany. http://ww2.bgbm.org/herbarium/ (consultado diciembre de 2019).

de la Cerda-Lemus, M. 1989. Encinos de Aguascalientes. Universidad Autónoma de Aguascalientes. Aguascalientes, México. $84 \mathrm{pp}$.

de la Cerda-Lemus, M. 1996. Las Gramíneas de Aguascalientes. Universidad Autónoma de Aguascalientes. Aguascalientes, México. 212 pp.

de la Cerda-Lemus, M. 2004a. Agavaceae. Scientiae Naturae 6(2): 19-44.

de la Cerda-Lemus, M. 2004b. Alliaceae. Scientiae Naturae 6(2): 45-56.

de la Cerda-Lemus, M. 2011a. La familia Burseraceae en el estado de Aguascalientes, México. Acta Botanica Mexicana 94: 1-25. DOI: https://doi.org/10.21829/abm94.2011.269

de la Cerda-Lemus, M. 2011b. Familia Euphorbiaceae en el Estado de Aguascalientes, México. Universidad Autónoma de Aguascalientes. Aguascalientes, México. 272 pp.

DMA. 1991. Technical Report 8350.2: World Geodetic System 1984, its definition and relationships with local Geodetic Systems. 2nd ed. The Defense Mapping Agency. Springfield, USA. 169 pp.

Dorr, L. y J. Wiersema. 2010. Typification of names of American species of vascular plants proposed by Linnaeus and based on Loefling's Iter Hispanicum (1758). Taxon 59(5): 15711577. DOI: https://doi.org/10.1002/tax.595021

Douglas, N. y R. Spellenberg. 2010. A new tribal classification of Nyctaginaceae. Taxon 59(3): 905-910. DOI: https://doi. org/10.1002/tax.593018

Engelmann, G. 1986. Instructions for the collection and preservation of botanical specimens. Annals of the Missouri Botanical Garden 73(3): 504-507. DOI: https://doi. $\operatorname{org} / 10.2307 / 2399189$
Fay, J. J. 1980. Nyctaginaceae. Flora de Veracruz 13: 1-54.

Fawcett, W. y A. B. Rendle. 1914. Nyctaginaceae. Flora of Jamaica 3: 145-154.

García, E. 1964. Modificaciones al Sistema de Clasificación Climático de Köppen (para adaptarlo a las condiciones de la República Mexicana). Offset Larios, S.A. México, D.F., México. 90 pp.

García-Regalado, G., O. Rosales-Carrillo, M. de la Cerda-Lemus y M. E. Siqueiros-Delgado. 1999. Listado Florístico del Estado de Aguascalientes. Scientiae Naturae 1(2): 5-51.

Google Earth. 2019. Google Earth, versión 7.3. Mountain View, EUA. https://www.google.com/intl/es/earth/download/gep/ agree.html (consultado noviembre de 2019).

Harriman, N. A. 1999. Synopsis of the New World Commicarpus (Nyctaginaceae). Sida 18(3): 679-684.

Hernández-Ledesma, P. 2018. Nyctaginaceae. Flora Del Valle de Tehuacán-Cuicatlán. Nueva serie publicación digital. Instituto de Biología, Universidad Nacional Autónoma de México. Cd. Mx., México. Pp. 1-61.

Hernández-Ledesma, P. y H. Flores-Olvera. 2003. Nyctaginaceae de Hidalgo, México. Anales del Instituto de Biología, Universidad Nacional Autónoma de México, Serie Botánica 74(2): 231-287.

Hernández-Ledesma, P., W. G. Berendsohn, T. Borsch, S. Von Mering, H. Akhani, S. Arias, I. Castañeda-Noa, U. Eggli, R. Eriksson, H. Flores-Olvera, S. Fuentes-Bazán, G. Kadereit, C. Klak, N. Korotkova, R. Nyffeler, G. Ocampo, H. Ochoterena, B. Sanchez, B. O. Schlumpberger y P. Uotila. 2015. A taxonomic backbone for the global synthesis of species diversity in the angiosperm order Caryophyllales. Willdenowia 45(3): 281-383. DOI: https://doi.org/10.3372/wi.45.45301

JSTOR. 2018. JSTOR Global Plants. https://plants.jstor.org/ (consultado noviembre de 2019).

Judd, W. S., C. S. Campell, E. A. Kellogg, P. F. Stevens y M. J. Donoghue. 2016. Plant Systematics: A Phylogenetic Approach. 4th ed. Sinauer Associates. Sunderland, USA. 677 pp.

K. 2018. Royal Botanic Gardens, Kew, Herbarium Catalogue. http://apps.kew.org/herbcat/gotoSearchPage.do (consultado noviembre de 2019).

Kellogg, E. A. 1988. Nyctaginaceae. Flora of the Lesser Antilles, Leeward and Windward Islands 4: 173-186.

Le Duc, A. 1993. Mirabilis. In: Jarvis, C. E., F. R. Barrie, D. M. Allen y J. L. Reveal (eds.). A list of Linnaean generic names and their 
types. Serie Regnum Vegetabile 127. International Association for Plant Taxonomy. Königstein, Germany. Pp. 6.

Martínez-Calderón, V. M., M. E. Siqueiros-Delgado y J. MartínezRamirez. 2017. Checklist of the genus Quercus (Fagaceae) of Aguascalientes, México. Check List, the Journal of Biodiversity Data 13(1): 1-22. DOI: https://doi. org/10.15560/13.1.2045

Morrone, J., T. Escalante y G. Rodríguez-Tapia. 2017. Mexican biogeographic provinces: Map and shapefiles. Zootaxa 4277(2): 277-279. DOI: https://doi.org/10.11646/zootaxa.4277.2.8

NY. 2018. The New York Botanical Garden, C. V. Starr Virtual Herbarium. New York, USA. http://sweetgum.nybg.org/science/vh/ (consultado noviembre de 2019).

P. 2018. Muséum national d'Histoire naturelle, Vascular Plants. Paris, France. https://science.mnhn.fr/institution/mnhn/ collection/p/list (consultado noviembre de 2019).

Pérez-Alvarado, L. A., R. Fernández-Nava y M. de la L. ArreguínSánchez. 2000. La familia Nyctaginaceae en la cuenca del río Balsas, México. Polibotánica 11: 49-109.

QGIS. 2017. Quantum GIS Geographic Information System v. 2.28.4. Quantum GIS Development Team. Open Source Geospatial Foundation Project. Vienna, Austria.

Sandoval-Ortega, M. H. y M. E. Siqueiros-Delgado. 2018. Las Familias Aizoaceae, Molluginaceae y Phytolaccaceae (CaryophyIlales) en el Estado de Aguascalientes, México. Polibotánica 46: 27-47. DOI: https://doi.org/0.18387/polibotanica.46.2

Sandoval-Ortega, M. H. y M. E. Siqueiros-Delgado. 2019. Reseda luteola L. en el estado de Aguascalientes, México. Investigación y Ciencia de La Universidad Autónoma de Aguascalientes 27(76): 5-10.

Sandoval-Ortega, M. H., M. E. Siqueiros-Delgado, J. Sosa-Ramírez y R. Cerros-Tlatilpa. 2017. Amaranthaceae (Caryophyllales) richness and distribution in the state of Aguascalientes, Mexico. Botanical Sciences 95(2): 203-220. DOI: https://doi. org/10.17129/botsci.909

Sandoval-Ortega, M. H., M. E. Siqueiros-Delgado, R. Cerros-Tlatilpa y G. Ocampo. 2019. La familia Caryophyllaceae en el estado de Aguascalientes, México. Acta Botanica Mexicana 126: e1455. DOI: https://doi.org/10.21829/abm126.2019.1455

Siqueiros-Delgado, M. E. 1989. Coníferas de Aguascalientes. Universidad Autónoma de Aguascalientes. Aguascalientes, México. 68 pp.
Siqueiros-Delgado, M. E. 1996. Leguminosas de Aguascalientes. Universidad Autónoma de Aguascalientes. Aguascalientes, México. 193 pp.

Siqueiros-Delgado, M. E. y G. González-Adame. 2006. Helechos y Plantas afines de Aguascalientes. Universidad Autónoma de Aguascalientes. Aguascalientes, México. 181 pp.

Siqueiros-Delgado, M. E., G. García-Regalado, C. Macías-Flores y O. Rosales-Carrillo. 2011. Malvales del Estado de Aguascalientes: Bombacaceae, Cistaceae, Malvaceae, Sterculiaceae y Tiliaceae. Universidad Autónoma de Aguascalientes. Aguascalientes, México. 172 pp.

Siqueiros-Delgado, M. E., J. A. Rodríguez-Avalos, J. MartínezRamírez y J. C. Sierra-Muñoz. 2016. Situación actual de la vegetación del estado de Aguascalientes, México. Botanical Sciences 94(3): 455-470. DOI: https://doi.org/10.17129/ botsci.466

Siqueiros-Delgado, M. E., J. A. Rodríguez-Avalos, J. Martínez-Ramírez, J. C. Sierra-Muñoz y G. García-Regalado. 2017. Vegetación del Estado de Aguascalientes. Universidad Autónoma de Aguascalientes, Comisión Nacional para el Conocimiento y Uso de la Biodiversidad. Aguascalientes, México. 368 pp.

Spellenberg, R. W. 2001. Nyctaginaceae. Flora Del Bajío y de regiones adyacentes 93: 1-96.

Spellenberg, R. W. 2003. Nyctaginaceae. In: Editorial Committee (ed.). Flora of North America North of Mexico Vol. 4. Oxford University Press. New York, USA. Pp. 14-74.

SPP. 1981. Síntesis geográfica del estado de Aguascalientes y anexo cartográfico. Secretaría de Programación y Presupuesto, Instituto de Estadística y Geografía. México, D.F., México. 98 pp.

Standley, P. C. 1911. The Allioniaceae of Mexico and Central America. Contributions from the United States National Herbarium 12: 303-389.

Standley, P. C. 1918. Allioniaceae. North American Flora 21(3): 171-254.

Standley, P. C. y J. A. Steyermark. 1946. Nyctaginaceae. Flora of Guatemala 24(IV): 174-192.

Stevens, P. C. 2001. Angiosperm Phylogeny Website. http://www. mobot.org/MOBOT/research/APweb/ (consultado octubre de 2019).

Thiers, B. 2019. Index Herbariorum. A global directory of public herbaria and associated staff. New York Botanical Garden's 
Virtual Herbarium. http://sweetgum.nybg.org/science/ih (consultado mayo de 2020).

TROPICOS. 2018. Tropicos.org, Missouri Botanical Garden. http:// www.tropicos.org/ (consultado diciembre de 2019).

US. 2018. Botany Collection, National Museum of Natural History. Smithsonian Institution. https://collections.nmnh.si.edu/ search/botany/ (consultado diciembre de 2019).

Villaseñor, J. L. 2016. Checklist of the native vascular plants of Mexico. Revista Mexicana de Biodiversidad 87(3): 559-902. DOI: https://doi.org/10.1016/j.rmb.2016.06.017

Villaseñor, J. L. y F. J. Espinosa-García. 1998. Catálogo de malezas de México. Fondo de Cultura Económica. México, D.F., México. 448 pp.
Villaseñor, J. L. y F. J. Espinosa-García. 2004. The alien flower plants of Mexico. Diversity and Distributions 10(2): 113-123. DOI: https://doi.org/10.1111/j.1366-9516.2004.00059.x

Weberling, F. 1985. Aspectos modernos de la morfología de las inflorescencias. Boletín de la Sociedad Argentina de Botánica 24: 1-28.

Whitehouse, C. 1996. Nyctaginaceae. In: Polhill, R. M. (ed.). Flora of Tropical East Africa, vol. 1. Royal Botanical Gardens, Balkema. Rotterdam, Netherlands. Pp. 1-19.

Zavala-Téllez, S. y R. M. Fonseca. 2014. Nyctaginaceae. Flora de Guerrero 63: 15-86. 